\title{
Beneficios e impactos de la implementación de normas técnicas en las organizaciones: una revisión sistemática*
}

\section{Benefits and impacts of the of technical norms implementation in organizations: systematic review}

Recibido: 30 de noviembre de 2015

Revisado: 22 de julio de 2016

Aceptado: 15 de agosto de 2016

Constanza Cristina Día Romero**

Consultor independiente

Yuber Liliana Rodríguez-Rojas****

Universidad Santo Tomás

\section{RESUMEN}

Este artículo busca analizar los beneficios e impactos a nivel interno y externo de la implementación de sistemas de gestión normalizados en las organizaciones. Para ello, se realizó una revisión sistemática exploratoria en las bases de datos Business Source Complete, Ebsco, SocINDEX y Proquest, siguiendo la metodología propuesta por Manchado, Tamames, López, Mohedano et al. (2009), de artículos publicados entre 1997 y 2014. El análisis se efectuó desde cinco categorías de beneficios e impactos en la gestión, la imagen, las personas, la productividad y el mercado. Los resultados muestran que, independientemente del sector económico, implementar una norma técnica

* Artículo de resultado de investigación.

* Comunicadora Social Institucional; especialista en Administración de Empresas y magíster en Calidad y Gestión Integral. Consultor independiente. Correo electrónico: constanza.cristina.diaz.r@gmail.com.

*** Fisioterapeuta; magíster en Salud y Seguridad en el Trabajo y doctorado en curso en Administración. Docente de la Maestría en Calidad y Gestión Integral, convenio Universidad Santo Tomás -Instituto Colombiano de Normas Técnicas y Certificación (Icontec). Correo e: yuberliliana@gmail.com. 
ISO en la gran mayoría de los casos, mejora los resultados sobre el mercado y la productividad.

Palabras clave: beneficios, gestión, ISO, sistema de gestión.

\section{ABSTRACT}

This paper analyzes the benefits and impacts internally and externally of the implementation of standardized management systems in organizations. To do this, an exploratory systematic review in databases was performed: Business Source Complete, EBSCO, Proquest SocINDEX and, following the methodology proposed by Spotted et al, of articles published between 1997 and 2015. The analysis was conducted under five. Categories of benefits and impacts on: management, image, people, productivity, and market. The results show that regardless of the economic sector, the benefits of implementing a technical standard ISO, in most cases get better results on the market and productivity.

Keywords: benefits, management, ISO, management system, Production Management

\section{INTRODUCCIÓN}

Si bien es cierto que existen organismos de normalización o estandarización a nivel nacional o regional, como en el Reino Unido el British Standards Institution (BSI), en Francia la Association Française de Normalisation (AFNOR) y en Alemania el German Institute for Standardization (DIN), entre otras, la organización que reúne todos los intereses y necesidades a nivel mundial es la Organización Internacional de Normalización (ISO) (en inglés International
Organization for Standardization), organización no gubernamental que ocupa una posición intermedia especial entre los sectores público y privado, porque, por un lado, muchos de sus institutos miembros forman parte de la estructura gubernamental de sus países, o están obligados por su Gobierno; por otro lado, algunos miembros de la ISO son únicamente del sector privado, ya que han sido creados por asociaciones nacionales de la industria. ISO actúa como una organización puente en el que puede alcanzarse un consenso sobre las soluciones que cumplan tanto los requisitos de los negocios, como las necesidades más amplias de la sociedad; además, es la organización más grande del mundo en el desarrollo de las normas. Desde 1947 hasta hoy, ha publicado más de 18.000 normas internacionales, que van desde las normas para las actividades como la agricultura y la construcción, a través de la ingeniería mecánica, a los productos sanitarios, hasta la evolución más reciente de la tecnología de la información (ISO, 2011).

En los artículos revisados, todos los autores hablan de normalización, pero ¿qué se entiende por ella? Según la ISO es el proceso de formular, emitir (publicar) e implementar normas técnicas o voluntarias. Las normas tienen diez objetivos primarios, que a su vez pueden ser llamados beneficios de la normalización (de acuerdo con el resultado arrojado por esta revisión sistemática exploratoria). La mayoría de los objetivos se explican por sí solos.

Aptitud para el uso, normas de producto, método de pruebas de ensayo y calibración, y normas de control de calidad; intercambiabilidad, es posible hacer procesos, productos o servicios intercambiables, aún si ellos fueron creados en diferentes países. Por ejemplo, las hojas de corte de diferentes marcas pueden ser diseñadas para ser utilizadas en la misma navaja; reducción de variedad; compatibilidad, por ejemplo, en el procesamiento electrónico de datos, la información tiene que 
ser codificada para el almacenamiento, la transmisión y recuperación con forma de pulsos electrónicos, para hacer que el código sea reconocible por cualquier máquina y, todo el tiempo, tiene que ser normalizada.

Esta normalización contribuye a establecer la compatibilidad entre varias máquinas o subsistemas y cuenta con permisos de ampliación y el intercambio de información entre diferentes sistemas; protección contra los factores que afectan la salud y la seguridad de los consumidores; protección del medio ambiente; mejor uso de los recursos (financieros, materiales y esfuerzo humano); mejor comunicación y entendimiento, por ejemplo, en lugares públicos como aeropuertos, estaciones de ferrocarril y carreteras, los signos normalizados desempeñan un papel importante; transferencia de tecnología y eliminación de barreras comerciales, los compradores pueden convencerse sobre el nivel de calidad de un producto que ha sido fabricado de acuerdo con una norma técnica reconocida (United Nations Industrial Development Organization [Unido], 2006).

Aunque en los anteriores diez objetivos de la normalización no se menciona explícitamente el beneficio económico, hay que tener en cuenta que los recursos destinados en la producción de las normas técnicas y las formas como estas cambian el comportamiento de la gente inevitablemente tienen un efecto económico. Asimismo, muchas de las normas técnicas no están diseñadas para un resultado económico específico, sino para aumentar la seguridad o administrar el riesgo. En la medida en que los accidentes o riesgos conducen a costos desde su prevención mediante el uso de normas técnicas, tiene un efecto económico en las organizaciones.

Además de los diez objetivos de la normalización, y debido a su propia definición, la normalización técnica o voluntaria tiene también otro propósito y es el logro máximo de la economía global. Las normas técnicas proporcionan beneficios a los diferentes sectores de la sociedad; algunos de los beneficios generales de la normalización técnica son los siguientes (Unido, 2006):

Normas técnicas para la fabricación:

- Racionalizar los procesos de fabricación.

- Eliminar o reducir el desperdicio de trabajo o material.

- Reducir inventarios de materia prima y productos terminados.

- Reducir el costo de fabricación.

Normas técnicas para los clientes:

- Asegurar la calidad de los bienes adquiridos y servicios recibidos.

- Proporcionar una mejor relación calidad-precio.

- Son convenientes para la solución de controversias, en su caso, con los proveedores.

Normas técnicas para los vendedores-comerciantes

- Proporcionar una base viable para la aceptación o el rechazo de los bienes o los consecuentes conflictos, si los hubiere.

- Minimizar retrasos, correspondencia, etc., como resultado de especificación incorrecta o incompleta de materiales o productos.

Norma técnica para los técnicos

- Proporcionar puntos de partida para la investigación y desarrollo, para seguir mejorando los bienes y servicios. 
Pero también las normas internacionales de ISO contribuyen a beneficiar a los consumidores, las empresas, los Gobiernos y la sociedad en general de las siguientes maneras (Unido, 2006):

- Para los consumidores: la conformidad de los productos y servicios con estándares internacionales ofrece garantía a los consumidores sobre la calidad, la seguridad y la confiabilidad de estos productos y servicios.

- Para las empresas: en la adopción de normas técnicas internacionales, los proveedores pueden llevar a cabo el desarrollo de sus productos y servicios sobre la base de las especificaciones que han sido de amplia aceptación en su sector, lo que facilita la contratación y organización de los bienes y producto. Esto a su vez significa que las empresas internacionales que utilizan normas técnicas son cada vez más libres de competir en muchos más mercados en todo el mundo.

- Para todos: las normas técnicas internacionales pueden contribuir a la calidad de vida en general, por garantizar que los modos de transporte, maquinaria y herramientas que utilizamos sean seguros.

- Para el planeta: las normas técnicas internacionales en aire, el agua, la calidad del suelo, y sobre las emisiones de gases y la radiación, pueden contribuir a los esfuerzos por preservar el medio ambiente.

Cada día la competencia se hace más grande entre las empresas, el mercado local o nacional se vuelve insuficiente para consumir los bienes y servicios que se producen; es por ello que las empresas buscan ampliar sus nichos de mercado internacionalizando sus productos, pero cuando lo hacen se enfrentan a los estándares de calidad y seguridad que el mercado internacional en cabeza de la Organización Mundial de Comercio (OMC) les impone. Es allí donde deben tomar la decisión de adoptar normas técnicas internacionales, bien sea de producto o de sistema de gestión o de ambas, en busca de una solución y un apoyo para subsistir en el largo plazo, más que por decisión propia. Pero las empresas no solo adoptan o implementan normas técnicas 0 voluntarias para conseguir beneficios económicos y así satisfacer sus necesidades, como se puede observar en la revisión que es objeto de este artículo, donde los autores de distintos países han hecho mediciones aisladas, rigurosas o no, sobre el impacto o efecto de esos beneficios.

Esta revisión sistemática exploratoria se realizó con el ánimo de identificar los beneficios, impactos 0 efectos más comunes, así como el método utilizado en las organizaciones desde la implementación de las normas técnicas emitidas por la ISO, para los sistemas de gestión estén o no certificados, a partir de los estudios que han sido desarrollados por investigadores particulares y por organismos de normalización técnica nacionales y otros equipos de investigación externa en países miembros de la ISO. Los estudios relacionadaos con las normas ISO han seguido una gran diversidad de enfoques, desde evaluaciones macroeconómicas para estudios relacionados con el impacto económico de las normas técnicas individuales o conjunto de normas técnicas, hasta evaluaciones de microeconomía en las empresas.

El tema de la normalización técnica de sistemas de gestión y sus relaciones con aspectos económicos y sociales se aborda en un gran número de publicaciones, en libros, artículos de investigación y otras publicaciones académicas. Sin embargo, hay un número limitado de estudios basados en investigaciones de campo original y publicados en la última década, en particular si el alcance del análisis es de interés general (es decir, no sectoriales). 


\section{METODOLOGÍA}

Este artículo presenta los resultados de una revisión sistemática exploratoria efectuada en las bases de datos Business Source Complete, Ebsco, SocINDEX y Proquest, así como en la página de la ISO, donde se encuentra un micrositio especial para los beneficios de la normalización o normas técnicas (www.iso.org/ iso/benefits_of_standards). Este micrositio es de conocimiento de una de las autoras, por su participación en el caso de estudio de la ISO en una empresa de Colombia en 2011, para la aplicación de la metodología ISO - medición de los beneficios económicos. Los artículos incluidos en la revisión proceden de distintos países del mundo y describen estudios realizados en distintos sectores de la economía.

Para el periodo o ventana de observación, inicialmente no se utilizó una restricción por fecha de publicación, pero al momento de depurar los artículos se encontraron algunos que están entre 1997 al 2014. Otro de los criterios considerados en esta revisión fue que los estudios refirieran en su título la variable de beneficios o de impacto, así como cualquier norma técnica generada por la ISO. Este criterio arrojó artículos únicamente relacionados con las normas ISO 9000, ISO 9001, ISO 14001, ISO 22000 e ISO 10002, es decir, que la ecuación de búsqueda utilizad fue Benefits AND Standardization AND ISO, en idioma inglés, pues en idioma español son muy pocos los artículos encontrados en la búsqueda; además, la investigación era a nivel mundial.

Los criterios utilizados para la selección de los artículos consistió inicialmente en que tuvieran las variables de la ecuación de búsqueda, en el título o en el resumen; por lo tanto, de los 737 artículos arrojados por la búsqueda en todas las bases de datos, solo 48 contenían las variables de la búsqueda. Posteriormente se revisaron los resúmenes de cada artículo, donde se buscaba exactamente la relación de los beneficios de las normas técnicas de sistema de gestión, en los resultados del estudio y, por último, que el estudio estuviera completo y disponible, fueron en total 36 artículos indexados (algunos no se incluyeron porque la base de datos que los contenía cobraba para poder descargar el artículo completo). En la figura 1 se presentan de manera gráfica los criterios tenidos en cuenta para la selección de los artículos indexados.

Figura 1. Procedimiento de selección de artículos indexados

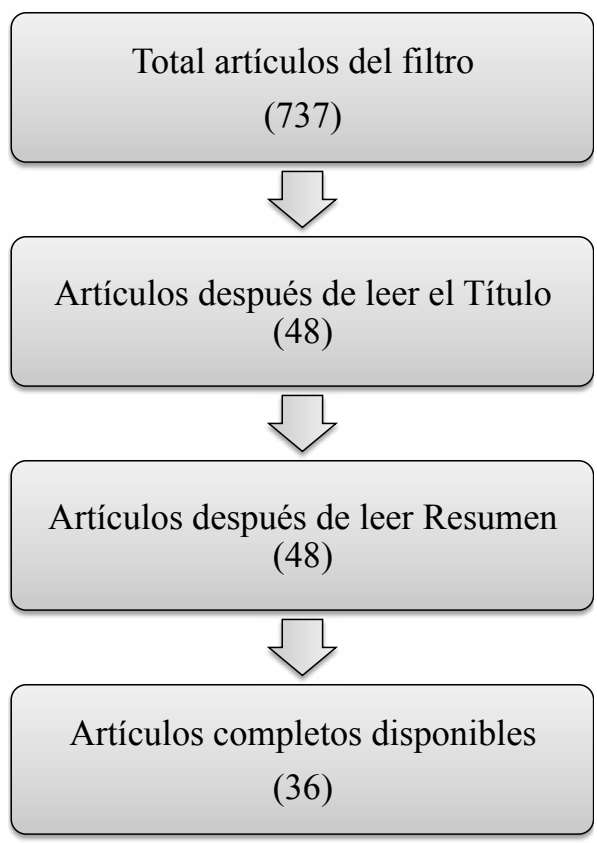

Fuente: elaboración propia.

Además, como se mencionó al inicio de este apartado, se incluyeron los resultados de los estudios realizados por dos organismos de normalización nacional de Alemania y Francia (DIN y AFNOR), cada uno de ellos llevados a cabo en años distintos, con bajo la misma metodología. Por último, se incluyó un artículo corto de la ISO (brochure. que resume todos los estudios realizados a la fecha por los organismos de normalización nacional de los países miembros de la ISO y la OMC (WTO, 2005), para un gran total de 39 artículos. 


\section{RESULTADOS}

En los 39 artículos analizados se evidenciaron beneficios, impactos o efectos comunes relacionados con el mercadeo y la productividad. Se encontró un artículo de 1997 que aunque refiere versiones anteriores de la norma ISO 9001, deja en evidencia la necesidad que tienen las organizaciones y los sectores de conocer el aporte que trae la implementación de las normas técnicas ISO de sistemas de gestión (algunos autores hablan de eficacia [Boiral, 2012]), desde hace mucho tiempo. En la figura 2 se puede ver la distribución de artículos por año, donde el año con más números de artículos publicados es 2013 con 7 artículos, seguido de 1999, con 6.

También se realizó un análisis en cuanto a los países donde se publicaron los artículos, y el país con más publicaciones relacionadas con el objetivo de esta revisión es Estados Unidos, con 6 artículos, seguido por el Reino Unido, con 5. En la figura 3 se puede apreciar la relación de los países por número de artículos publicados.

Por último, la estadística de los artículos que se centraron en una o varias disciplinas de las normas técnicas ISO u otras normas, como calidad (ISO $9000 \mathrm{y}$ 9001), ambiental (ISO 14001), seguridad alimentaria (ISO 22000), tratamiento de quejas (ISO 10002) y varias ISO (los artículos que mencionan en su contenido beneficios generales de varios estándares, sin profundizar en alguno específico), se pueden ver en la figura 4.

Para un panorama general de los artículos revisados, se realizó una gráfica de la distribución de los artículos por disciplina, por año y por país, que se observa en la figura 5.

La clasificación de los beneficios/impactos o efectos de la implementación de las normas técnicas ISO es distinta para cada uno de los autores, como es el caso de Chang y Lo $(2005,2007)$ y Dick (2009) que coinciden en clasificar los "beneficios en internos y externos; otros autores no los denomina beneficios, sino "enseñanzas" (Miotti, 2009). Padma, Ganesh y Rajendran (2006) los llaman "Efectos de la certificación ISO en los Factores Clave y los Indicadores de desempeño organizacional" y Boiral, 2012) los clasifica en cuatro categorías principales (beneficios organizacionales, beneficios de gestión y estratégicos, dificultades y factores de contingencia), donde cada una se clasifica en impactos internos, que a su vez se organiza en aspectos como la operación y calidad, y en impactos externos, con los aspectos: clientes y proveedores (en la tabla 1 se despliega en detalle cada uno de los aspectos de esta y cada una de las clasificaciones). Otros autores no los clasifican, solo listan los beneficios y los demás los catalogan como beneficios:

- Operativos y estratégicos del negocio (Beattie y Sohal, 1999).

- No económicos y económicos (Alberti, Caini y Calabrese, 2000).

- Anticipados de la certificación y beneficios actuales (Stevenso y Barnes, 2001; Skrabec, Ragu-Nathan, Rao y Bhatt, 2001).

- Resultados financieros, cliente/consumidor, trabajadores y resultados operacionales (Karapetrovic, Fa y Saizarbitoria, 2010) (Casadesús y Karapetrovic, 2005).

- De gestión, de los recursos humanos y del producto (Teixeira y Sampaio, 2013).

- Organizacionales y de mercado (Wolniak, 2011).

- Económicos (Weissinger, 2014). 
Figura 2. Artículos por año de publicación

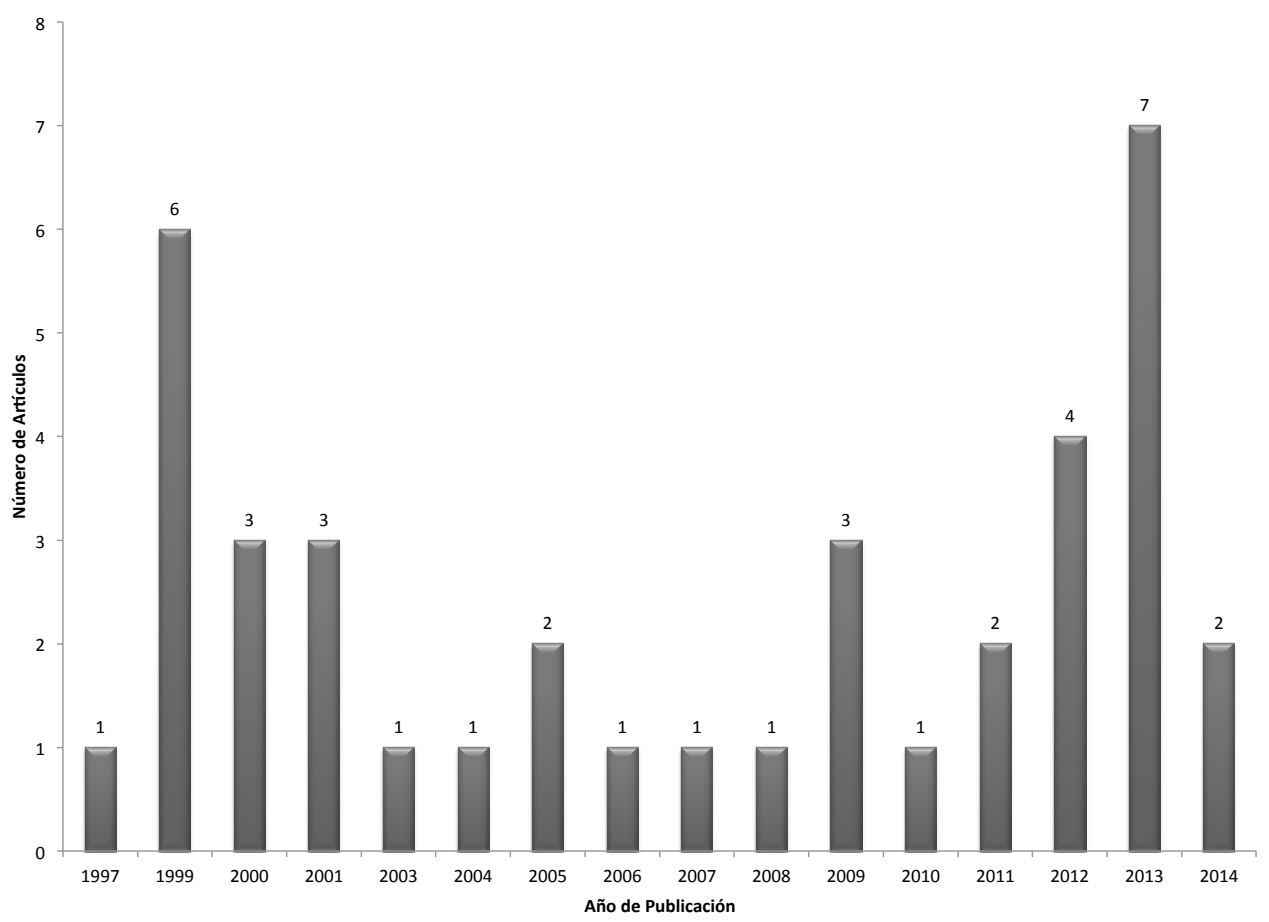

Fuente: elaboración propia.

Figura 3. Artículos por país de publicación

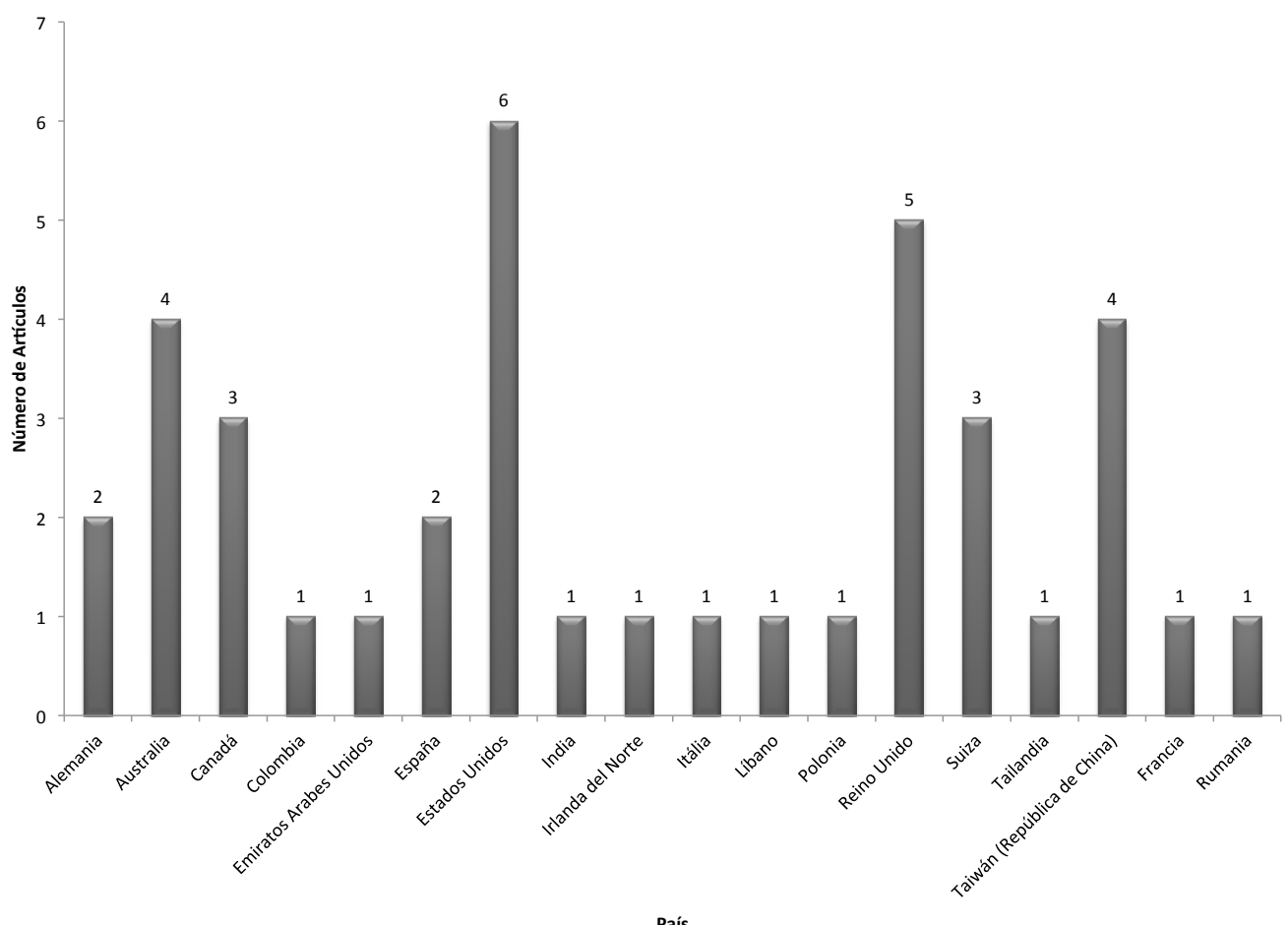

Fuente: elaboración propia. 
Constanza Cristina Díaz Romero, Yuber Liliana Rodríguez-Rojas

Figura 4. Artículos por disciplina de las normas técnicas ISO y otras

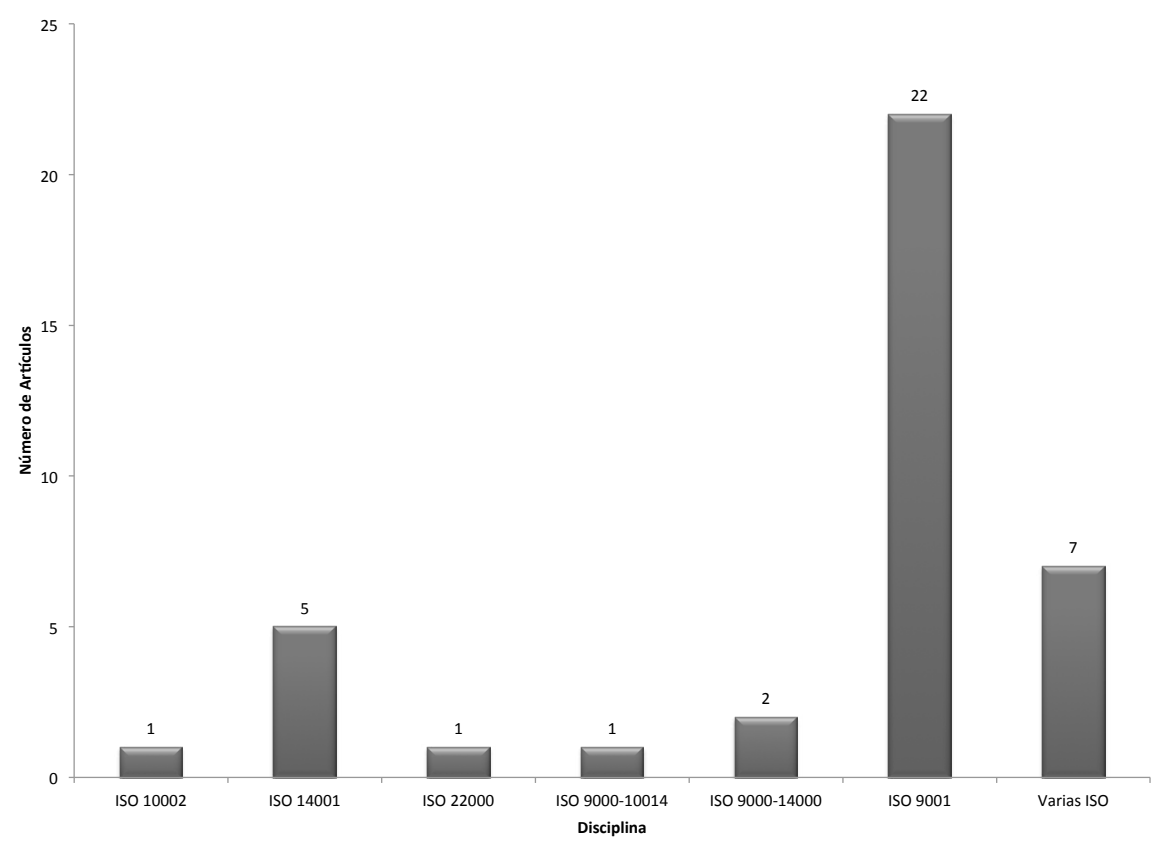

*Varias ISO (los artículos que mencionan en su contenido beneficios generales de todos los estándares, ninguno específico)

Fuente: elaboración propia.

Figura 5. Distribución de los artículos por disciplina, año y país

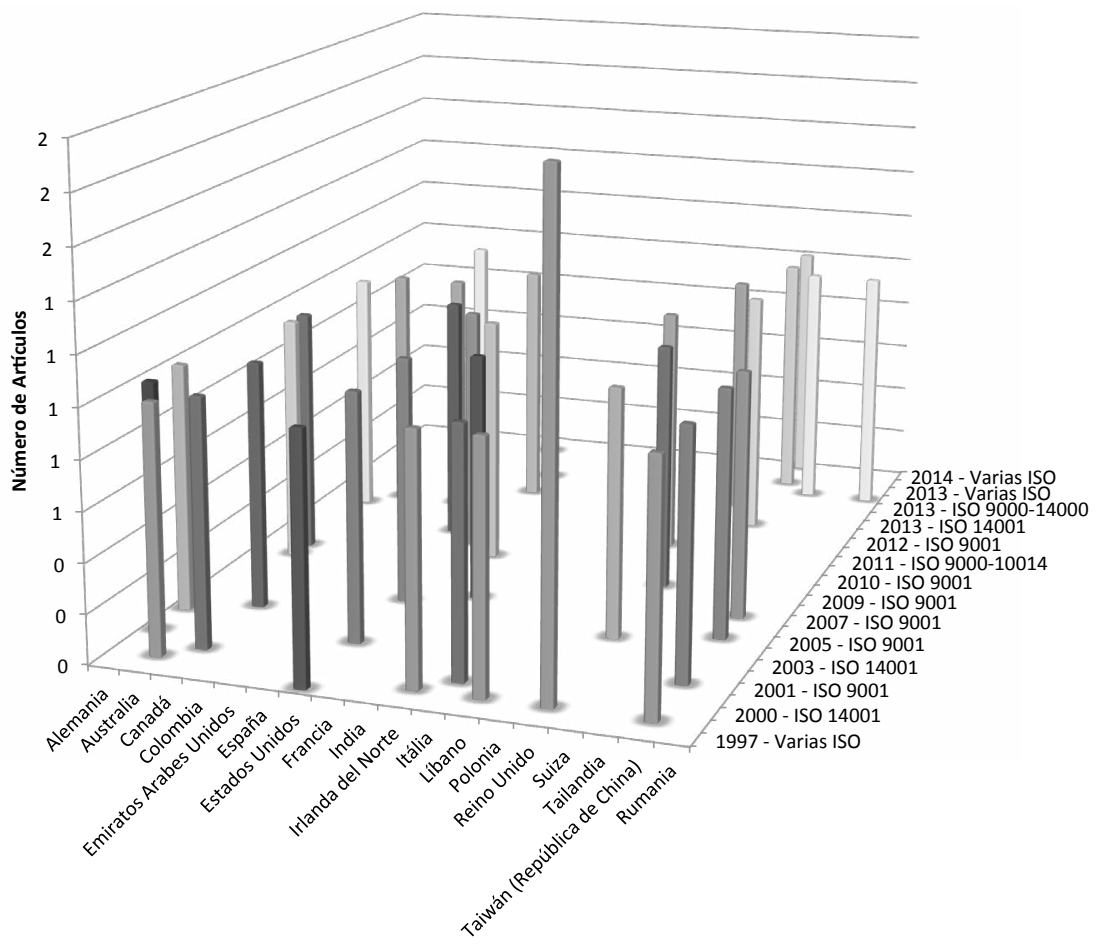

Fuente: elaboración propia. 
Teniendo en cuenta que no hay unificación de criterios para la clasificación de los resultados de la medición de las normas técnicas, a causa de la naturaleza relativamente homogénea de la literatura actual en términos de las metodologías y los tipos de variables por medir (Boiral, 2011, 2012), se realiza un nuevo agrupamiento de los aspectos relacionados por los autores como beneficios/impactos/efectos, en cinco categorías: gestión, productividad, personas, imagen de la organización y mercado (ver tabla 1).

En cuanto a los métodos utilizados para la identificación de los beneficios o impactos, el más utilizado es la encuesta (cuestionarios enviados por correo) con 15 artículos o acompañada de entrevista realizada por profesionales especializados en la norma técnica objeto de estudio (6 artículos), lo cual hace que el resultado sea subjetivo, en la medida que se recopila la percepción de los gerentes generales o gerentes encargados de la implementación de la norma técnica de sistema de gestión.

Wolniak (2011) hace mención de la norma ISO 10014:2006 Gestión de la calidad - Directrices para la obtención de beneficios financieros y económicos, para indicar que proporciona a la alta dirección métodos y herramientas de gestión para mejorar constantemente la ejecución y el desarrollo de la gestión de la calidad. Con estos se pueden conseguir los beneficios económicos y financieros allí relacionados como ejemplos, los cuales el autor plasma después de una revisión con expertos en una encuesta que tabula utilizando el método k-means (k-medias), sin desarrollar la metodología que trae la norma.

Se tomó en cuenta la observación realizada por Boiral (2012) para no dejar por fuera las publicaciones realizadas por instituciones especializadas, como los organismos de certificación nacionales, que han desarrollado una metodología que evalúa el aspecto macroeconómico y microeconómico de la implementación de las normas técnicas, a partir de la recolección de información y datos directamente en las empresas de la muestra seleccionada y en los datos en los mismos organismos de certificación, así como la realización de entrevistas.

En esta revisión se encontraron seis artículos con metodologías, aplicadas a partir de los datos recolectados sin recurrir a entrevistas, y en otros casos utilizando las entrevistas.

Las metodologías aplicadas sin recurrir a las entrevistas son las siguientes:

- Modelo basado en la maximización de la utilidad (Nakamura, Takahashi y Vertinsky, 2001).

- Modelo de comercio intraindustrial o interindustrial (basado en indicadores de capacidad de innovación, evolución demanda y desempeño tecnológico) (Blind, 2001).

- Indicadores financieros (ROA, ROS) (Corbett, Montes-Sancho y Kirsch, 2005).

- Metodología longitudinal que mide los niveles de rendimiento (Saizarbitoria y Landín, 2011) (Saizarbitoria, Landín y Molina-Azorín, 2011).

- Técnica multivariada de análisis discriminante (MAD) (indicadores de productividad y financieros) (Morelos, Fontalvo, Vergara, 2013).

- Análisis del desempeño financiero (ROA) (Jong, Paulraj y Blome, 2014).

Las metodologías aplicadas en combinación con entrevistas son: 
- Metodología ISO para el cálculo de beneficios económicos (EBITDA) (Weissinger, 2014) (ISO, 2011) (ISO, 2012a) (ISO, 2013).

- Modelo de medición macroeconómico y microeconómico (Deutsches institut für Normung [DIN], 2000).

- Modelo de medición macroeconómico (Miotti, 2009)

Los anteriores modelos no se explican en detalle, por cuanto no es el alcance de esta revisión.

\section{DISCUSIÓN}

Los resultados de esta revisión muestran que, independientemente del sector económico donde se realizaron los estudios y de la metodología utilizada, los beneficios de implementar una norma técnica ISO para sistemas de gestión, en la gran mayoría de las veces, mejoran los resultados sobre el mercado (ventas, ingresos, satisfacción clientes) y sobre la productividad (operacionales: desperdicios, mejora de los tiempos), como se observa en la columna "Beneficios/impactos/ efectos" de la tabla 1. Como lo expresa Boiral (2012), los impactos operacionales de la norma ISO 9001 son los mencionados con mayor frecuencia en la literatura. Este énfasis refleja el propósito mismo de la norma, que se supone para mejorar la práctica de la gestión de la calidad con el fin de satisfacer las necesidades de los clientes y mejorar la eficacia. Por lo tanto, los beneficios operacionales son parte de lo que se espera de los objetivos explícitos de la norma.

Si se quieren cuantificar los beneficios de la categoría mercado, se debe hacer una aproximación al área contable 0 financiera de las empresas, pero este campo no se ha abordado con gran entusiasmo (Beattie y Sohal,
1999), solo lo han planteado los organismos de normalización nacionales como el de Alemania (DIN), el de Francia (AFNOR), entre otros, y el organismo internacional ISO, los cuales han tomado en cuenta que la industria se ha preocupado cada vez más por valorar la eficiencia económica de la normalización y está más interesada en el papel de esta actividad; por lo tanto, los resultados sistemáticos y confiables solo se pueden lograr sobre una base común. "Debido a que hay una gran presión en la industria para reorganizarse racionalmente, los costos y beneficios de la normalización se deben examinar desde ambos puntos de vista, tanto el microeconómico como el macroeconómico" (DIN, 2000, p.6).

A pesar de las similitudes en los métodos y objetivos generales de la mayoría de los estudios, el impacto de la certificación de hecho fue interpretado y se mide de varias maneras. Por ejemplo, muchos indicadores pueden ser utilizados para medir la mejora de la calidad, como disminución en la tasa de defectos de producción, reducción del coste de mala calidad, entre otros (Boiral, 2012). Desde 2010 hasta la fecha, se encuentran estudios que calculan a través de indicadores financieros (ROA, ROE) la cuantificación de los beneficios de implementar alguna norma técnica, los cuales no incluyen el uso de costes de calidad o de no calidad para dichas mediciones, pues se centran en el resultado final del ejercicio financiero reportado por las empresas estudiadas. Se infiere que a la fecha no se ha realizado un estudio de los beneficios económicos, con base en los costes de calidad y de no calidad, como lo enseña la academia, lo cual sería una oportunidad para una futura investigación.

En esta revisión se pudo observar la relación que hay de los beneficios obtenidos en las distintas empresas encuestadas alrededor del mundo, en las cuales, en la medida que la decisión de implementar la norma técnica de sistemas de gestión fue debida a factores 
internos (decisión propia) o externos (por el cliente 0 la competencia), los beneficios fueron menores o mayores. Por ejemplo el hecho de que la ISO 9001 se implemente como una iniciativa de calidad independiente 0 como parte de una campaña más amplia puede tener un impacto sobre la organización que maximiza los beneficios gracias a la norma o la adopción de la norma ISO 9001 en organizaciones de servicios legales en Australia (Douglas, Kirk, Brennan y Ingram, 1999), impulsada por factores externos que están relacionados principalmente por sus proveedores, incluidos los servicios jurídicos, para que estén certificados con la norma ISO 9000, incluidas las empresas y agencias gubernamentales (Prajogo, 2008).

También se evidencia que en las encuestas de estos estudios revisados, algunas empresas son renuentes para mantener la certificación ISO 9001, ya sea porque perciben que el mantenimiento de la certificación es lento y costoso, o porque creen que el sistema de calidad no es más que el requisito mínimo para cualquier empresa. Es posible que estas empresas prevean que los beneficios resultantes desde el mantenimiento de la certificación no serían suficientes para continuar con los esfuerzos (Chang y Lo, 2005; Lo y Chang, 2007), lo que significa que no vieron beneficios directos con la implementación de la norma técnica de calidad.

En cambio, otros estudios resaltan la importancia de la implementación de las normas técnicas ISO para sistemas de gestión, en la innovación y en la apertura de nuevos mercados (exportación). Este es el caso de Suiza, donde los resultados muestran claramente que su capacidad innovadora y sus existencias de estándares son capaces de explicar su comportamiento de las exportaciones en los tres países (Alemania, Francia y Reino Unido), además de la función de importación, la balanza comercial y el comercio intraindustrial (Blind y Knut, 2001).
En cuanto a la innovación, los resultados también revelaron que las empresas certificadas en ISO 9001 son más proclives a incluir la reestructuración como parte de su filosofía de innovación, para aplicar el concepto de cliente interno a través de su organización, y así mejorar la cooperación, crear estructuras más planas, crear redes sociales, aplicar altos estándares de integridad y lograr la innovación de procesos radicales a través de la reingeniería. Terziovski y Guerrero-Cusumano (2009) distinguen entre innovaciones incrementales, que conducen a menores mejoras en productos o procesos, y las innovaciones radicales, que son más de carácter estratégico. Se puede entender que las normas técnicas son una de las formas de codificación del conocimiento, de manera semejante a las patentes. En conjunto con la innovación, en especial por su difusión, las normas técnicas permiten compartir la innovación, al tiempo que hacen evolucionar las buenas prácticas generales del mercado (Miotti, 2009). Pero también hay quienes no encuentran relación sobre el impacto de la certificación de calidad en el rendimiento de la innovación, sino que más bien la certificación ISO 9001 reprime la innovación.

Otros autores afirman que aunque la certificación ISO 9001 demuestra un nivel de reconocimiento internacional de la calidad, los resultados obtenidos en el estudio no apoyan la opinión respecto a que de la certificación ISO se puede esperar que esta conduzca a una mayor participación en el mercado y ventaja competitiva con el tiempo (Chang y Lo, 2005; Lo y Chang, 2007). En el estudio en Estados Unidos, tres años después de la certificación, las empresas certificadas no muestran un funcionamiento anormal fuertemente significativo en todas las especificaciones del grupo de control (Corbett et al., 2005); adicionalmente, la mayoría de los empleadores en Estados Unidos quiere saber si las ventajas financieras asociadas con la norma ISO 9001 e ISO 14001 superan los costos asociados con la obtención de estas certificaciones (Aba y Badar, 2013). 
La causa común puede ser que las empresas son más propensas a buscar nuevas prácticas o sistemas de gestión que puedan mejorar sus capacidades, que en última instancia, crean rendimiento superior a la media. Por lo tanto, la mejora en el rendimiento no es causada por cualquier sistema o práctica individual, sino que es el resultado acumulativo de un proceso de adopción, aprendizaje y adaptación continuo de la nueva práctica 0 sistema de gestión (Dick, 2009) (Dick, Heras y Casadesús, 2008). Como también lo manifiestan Moatazed-keivani, Ghanbari-parsa y Kagaya (1999) los beneficios de un sistema de control de calidad formal, que se entiende correctamente, diseñado de manera adecuada y bien implementado, son superiores a los efectos secundarios negativos.

Los artículos revisados en su mayoría desarrollan sus estudios en el sector industrial o manufacturero, muy pocos en el sector de los servicios, donde los clientes son cada vez más los consumidores finales, y en estos estudios no se revisa de manera significativa el impacto de las normas técnicas en los consumidores finales. Cuando en los beneficios de dichos estudios se menciona la satisfacción del cliente, se hace basado en la percepción de los proveedores (empresas estudiadas), en lugar de la percepción de los propios clientes. (Ferguson, 2004) donde los resultados serían otros. Sería otro interesante escenario de estudio futuro.

Una norma técnica estudiada y que no es certificable es la ISO 10002 para el tratamiento y manejo de las quejas. Se fundamenta en nueve principios rectores normativos: Visibilidad, accesibilidad, responsabilidad, objetividad, sin cargos (cobros), confidencialidad, enfoque en el cliente, rendición de cuentas y mejoramiento continuo. Apoya la planificación y diseño de los procesos de manejo y tratamiento de quejas, su funcionamiento, mantenimiento, mejora y auditoría. (Ang y Buttle, 2012). Esta norma técnica favorece los beneficios relacionados con la categoría que se estableció "sobre el mercado" en cuanto al marketing, sobre todo en términos de mejores niveles de defensa del cliente, niveles más altos de satisfacción del cliente, y la mejora en los procesos de cara al cliente (Ang y Buttle, 2012).

Se comparte la idea de Aba y Badar (2013) que las empresas certificadas en normas técnicas ISO de sistemas de gestión deben compararse con las empresas no certificadas para determinar si los beneficios de los indicadores financieros de desempeño son el resultado solamente de la norma técnica ISO. En el futuro, los autores planean llevar a cabo la investigación para abordar estas cuestiones.

\section{CONCLUSIONES}

Los resultados de algunos estudios indican que cuando las empresas buscan la certificación ISO de sistemas de gestión, quieren mejorar sus procesos de producción, control de gestión, y la consistencia de su línea de producción (Mezher y Ramadan, 1998), como es el caso de las empresas saudíes que cada vez son más conscientes de la ventaja competitiva de tener la certificación en la norma técnica ISO. Por lo tanto la norma técnica ISO de sistemas de gestión es sólo una herramienta que debe ser utilizado de una manera sensible y apropiada (Moatazed-Keivani, Ghanbari-Parsa y Kagaya, 1999).

Los sistemas de gestión ambiental (SGA) basados en la norma técnica ISO 14001 también refieren beneficios internos (empresa) y externos (comunidad), pero no cuantifican los beneficios externos económicos (Alberti et al., 2000). Cuando se decide por la implementación de una norma técnica ISO (certificable 0 no), es importante el rol que desempeñará la norma técnica en el escenario de la empresa y en el mercado. Por lo tanto, si se hace evidente que la certificación es 
necesaria para apoyar iniciativas para mejorar la competencia y la comercialización (mercadeo), la empresa puede comenzar el proceso, pero debe continuar con el conocimiento de que, en el corto plazo, obtener la certificación será costoso y lento. Los beneficios pueden ser alcanzados, pero se requiere una visión a largo plazo (Stevenson y Barnes, 2001).

Se debe ser consciente de que no solo hay beneficios y felicidad al implementar una norma técnica ISO de sistema de gestión, como lo refiere el estudio de las empresas de Canadá que implantaron y certificaron la ISO 14001; sin embargo, no se obtuvieron estos beneficios sin encontrar ciertos problemas durante el proceso. Entre los problemas que se consideran más importantes por las empresas encuestadas están las necesidades de formación de los empleados, así como la falta de participación del personal y de la gestión (Berthelot, McGraw, Coulmont y Moraill, 2003).

En general, la evidencia presentada en los estudios es compatible con la opinión de que un cuidadoso diseño e implementación de un sistema de gestión de calidad coherente y documentado puede contribuir significativamente al rendimiento financiero superior (Corbett et al., 2005).

Al encontrar en estos estudios una relación entre la mejora de los resultados empresariales y la adopción del sistema de gestión de calidad, es tentador inferir que la mejora del rendimiento se puede atribuir al cambio de sistema de gestión de calidad (posiblemente en combinación con alguna variable intermedia). Claramente, la evidencia presentada aquí por la presencia de un mecanismo de selección sugiere que las explicaciones contrarias a la intuición pueden ser igualmente válidas (Dick, 2009) (Dick et al., 2008).

La evidencia empírica sugiere que las empresas pueden obtener beneficios internos como mejoramientos en la calidad y en la productividad de sus procesos, además de lograr un mejor desempeño financiero, mantener 0 ampliar su sector de mercado y en general incrementar su valor, gracias a la implementación de iniciativas (Morelos et al., 2013).

Por otra parte, muy pocos estudios han impugnado los impactos positivos de la aplicación de la norma. En esta perspectiva, la ISO 9001 puede aparecer como una verdadera herramienta para mejorar la eficacia (Lo y Chang 2007). En cierta medida, estos beneficios están probablemente relacionados con el crecimiento exponencial en el número de certificaciones en todo el mundo (Boiral, 2012 y 2013).

Como conclusión, son más los estudios que utilizan métodos que recogen la percepción de los colaboradores (encuesta y entrevista), que los que utilizan métodos a partir de datos y estadísticas propias de las empresas, que sean comparables antes y después de la certificación.

Dado que esta revisión sistemática es exploratoria, no se profundizó en un contexto particular, por cuanto se recomienda desarrollar una revisión específica para el ámbito latinoamericano, de tal modo que se puedan analizar los beneficios de la implementación de estas normas estandarizadas en organizaciones de países en desarrollo. Por otra parte, se recomienda tener en cuenta para una futura investigación los efectos o impactos no deseables o desfavorables de la normalización.

Cabe señalar que esta revisión no vinculó análisis estadístico de los resultados obtenidos en cada una de las investigaciones estudiadas. Se limitó a un análsis cualitativo de los beneficios de la implementación de normas estandarizadas; por ende, una posible línea de investigación es el desarrollo de revisiones sistemáticas de corte cuantitativo y metanálisis que permitan cuentificar el impacto de la implementación de sistemas de gestión normalizados en organizaciones, tanto de paises desarrollados, como en proceso de desarrollo. 


\section{REFERENCIAS}

Aba, E. K. y Badar, M. A. (2013). A Review of the Impact of ISO 9000 and ISO 14000 Certifications. Journal of Technology Studies, 39(1), 42-50.

Alberti, M., Caini, L., Calabrese, A., Rossi, D. (2000). Evaluation of the costs and benefits of an environmental management system. International Journal of Production Research, 38(17), 4455-4466.

Allur, E., Heras-Saizarbitoria, I. y Casadesús, M. (2014). Internalization of ISO 9001: a longitudinal survey. Industrial Management \& Data Systems, 114(6), 872-885.

Ang, L. y Buttle, F. (2012). Complaints-handling processes and organisational benefits: An ISO 10002-based investigation. Journal of Marketing Management, 28(9-10), 1021-1042.

Beattie, K. R. y Sohal, A. S.(1999). Implementing ISO 9000: A study of its benefits among Australian organizations. Total Quality Management, 10(1), 95-106.

Berthelot, S., McGraw, E., Coulmont, M. y Moraill, J. (2003). ISO 14000: Added Value for Canadian Business? Environmental Quality Management, 13(2), 47-57.

Blind, K. (2001). The impacts of innovations and standards on trade of measurement and testing products: empirical results of Switzerland's bilateral trade flows with Germany, France and the UK. Information Economics and Policy, 13(4), 439-460.

Boiral, O.(2012). ISO 9000 and Organizational Effectiveness: A Systematic Review. Quality Management Journal, 19(3), 16-37.
Boiral, O. (2011). Managing with ISO Systems: Lessons from Practice. Long Range Planning, 44(3), 197-220.

Casadesús, M. y Karapetrovic, S. (2005). Has ISO 9000 lost some of its lustre? A longitudinal impact study. International Journal of Operations \& Production Management, 25(6), 580-596.

Chang, D. y Lo, L. (2005). Measuring the Relative Efficiency of a Firm's Ability to Achieve Organizational Benefits after ISO Certification. Total Quality Management, 16(1), 57-69.

Chu, P.-Y. y Wang, H.-J. (2001). Benefits, Critical Process Factors, and Optimum Strategies of Successful ISO 9000 Implementation in the Public Sector: An Empirical Examination of Public Sector Services in Taiwan. Public Performance $\mathbb{E} \mathrm{Ma}$ nagement Revierw, 25(1), 105-121.

Corbett, C. J., Montes-Sancho, M. J. y Kirsch, D. A. (2005). The Financial Impact of ISO 9000 Certification in the United States: An Empirical Analysis. Management Science, 51(7), 1046-1059.

Dick, G. P. M. (2009). Exploring performance attribution. The case of quality management standards adoption and business performance. International Journal of Productivity and Performance Management, 58(4), 311-328.

Dick, G. P. M., Heras, I. y Casadesús, M. (2008). Shedding light on causation between ISO 9001 and improved business performance. International Journal of Operations \& Production Management, 28(7), 687-708.

Deutsches Institut für Normung (DIN) (2000). Beneficios económicos de la normalización, Resumen de resultados. Reporte final y ejemplos prácticos., Wien: Deutsches Institut für Normung [DIN], Beuth Verlag GmbH Berlin. 
Douglas, A., Kirk, D., Brennan, C. y Ingram, A. (1999). Maximizing the benefits of ISO $9000 \mathrm{im}$ plementation. Total Quality Management, 10(4-5), S507-S513.

Ferguson, A.(2004). Do management standards benefit consumers? Consumer Policy Review, 14(2), 38-43.

Huarng, F., Horng, Ch. y Chen, C. (1999). A study of ISO 9000 process, motivation and performance. Total Quality Management, 10(7), 1009-1025.

International Organization for Standardization (ISO) (2006). ISO 10014: Gestión de calidad - Guía para analizar beneficios financieros y económicos, desde la aplicación de los principios de la gestión de la calidad ISO 9000. Bogotá: Instituto Colombiano de Normas Técnicas y Certificación [Icontec].

International Organization for Standardization [ISO] (2011). Economic benefits of standards - International case studies. Ginebra: autor.

International Organization for Standardization [ISO] (2012a). Economic benefits of standards - International case studies Volume 2. Ginebra: autor.

International Organization for Standardization [ISO] (2012b). What's the bottom line? Ginebra: autor-

International Organization for Standardization [ISO] (2013). Economic benefits of Standards - ISO Methodology 2.0. Ginebra: autor.

Jong, P., Paulraj, A. y Blome, C. (2014). The Financial Impact of ISO 14001 Certification: Top-Line, Bottom-Line, or Both? Journal of Business Ethics, 119(1), 131-149.

Karapetrovic, S., Casadesús, M. y Heras, I. (2010). What happened to the ISO 9000 lustre? An eight-year study. Total Quality Management, 21(3), 245-267.
Lertpachin, G., Wingwon, B. y Noithonglek, T. (2013). The effect of marketing focus, innovation and learning organization on the building of competitive advantages: empirical evidence from ISO 9000 certified companies. Journal of Strategic Marketing, 21(4), 323-331.

Lo, L. y Chang, D. (2007). The difference in the perceived benefits between firms that maintain ISO certification and those that do not. International Journal of Production Research, 48(5), 1881-1897.

Manchado, R., Tamames, S., López, M., Mohedano, L. et al. (2009). Revisiones Sistemáticas Exploratorias. Medicina y Seguridad del trabajo, 55(216), 12-19.

Magda, H. y Nabulsib, F.(2012). The Effectiveness of ISO 9000 in an Emerging Market as a Business Process Management Tool: the case of the UAE. Procedia Economics and Finance, (3), 158-165.

Mcadam, R. y Mckeown, M. (1999). Life after ISO 9000: An analysis of the impact of ISO 9000 and total quality management on small businesses in Northern Ireland. Total Quality Management, 10(2), 229-241.

Mezher, T. y Ramadan, H. (1998). The Costs and Benefits of Getting the ISO 9000 Certification in the Manufacturing Sector in Saudi Arabia. Quality Assurance, 6(2), 107-122.

Miotti, H. (2009). Impacto Económico de la Normalización. La Plaine Saint-Denis: AFNOR Normalisation.

Moatazed-Keivani, R., Ghanbari-Parsa, A. R. y Kagaya, S. (1999). ISO 9000 standards: perceptions and experiences in the UK construction industry. Construction Management and Economics, 17(1), 107-119. 
Morelos Gómez, J., Fontalvo, T. J. y Vergara, J. C. (2013). Incidencia de la certificación ISO 9001 en los indicadores de productividad y utilidad financiera de empresas de la zona industrial de Mamonal en Cartagena. Estudios Gerenciales, 29(126), 99-109.

Nakamura, M.,Takahashi, T. y Vertinsky, I. (2001). Why Japanese Firms Choose to Certify: A Study of Managerial Responses to Environmental Issues. Journal of Environmental Economics \& Management, 42(1), 23-52.

Padma, P., Ganesh, L. S. y Rajendran, C. (2006). A study on the critical factors of ISO 9001:2000 and organizational performance of Indian manufacturing firms. International Journal of Production Research, 46(18), 4981-5011.

Prajogo, D. I. (2008). The sustainability of ISO 9001 in a legal service organisation. The Service Industries Journal, 28(5), 603-614.

Ratnasingam, J., Yoon, C. Y. y Iora, F. (2013). The Effects of ISO 9001 Quality Management System On Innovation And Management Capacities In The Malaysian Furniture Sector. Bulletin of the Transilvania University of Braov, 6(1), 63-70.

Saizarbitoria, I. y Boiral, O. (2013). ISO 9001 and ISO 14001 towards a Research Agenda on Management System Standards. International Journal of Management Reviews, 15(1), 47-65.

Saizarbitoria, I. y Landín, G. (2011). Impacto de la certificación ISO 14001 en el rendimiento financiero empresarial: conclusiones de un estudio empírico. Cuadernos de Economía y Dirección de la Empresa (CEDE), 14(2), 112-122.

Saizarbitoria, I. Landín, G. y Molina-Azorín, J. (2011). Do drivers matter for tn benefits of ISO 14001?
International Journal of Operations \& Production Management, 31(2), 192-215.

Skrabec, Q. R., Jr., Ragu-Nathan, T. S., Rao, S. S. y Bhatt, B.T. (2001). ISO 9000: Do the Benefits Outweigh the Costs? Industrial Management, 39(6), 26-32.

Stevenson, T. H.; Barnes, F. C. (2001). Fourteen Years of ISO 9000: Impact, Criticisms, Costs, and Benefits. Business Horizon, 44(3), 45-51.

Teixeira, S. y Sampaio, P. (2013). Food safety management system implementation and certification: survey results. Total Quality Management, 24(3), 275-293.

Terziovski, M. y Guerrero-Cusumano, J.-L. (2009). ISO 9000 quality systems certification and its impact on Innovation performance. Academy of Management Annual Meeting Proceedings, 1, 1-6; doi:10.5465/AMBPP.2009.44252631.

United Nations Industrial Development Organization [Unido] (2006). Role of standards. A guide for small and medium-sized enterprises. Recuperado de https://www.unido.org/uploads/tx_templavoila/ Role_of_standards.pdf

Weissinger, R. (2014). Economic benefits of standards. PIK - Praxis der Informationsverarbeitung und Kommunikation, 37(3), 183-188.

Wolniak, R. (2011). The assessment of significance of benefits gained from the improvement of quality management systems in Polish organizations. Quality \& Quantity, 47(1), 515-528.

World Trade Organization [WTO] (2005), World Trade Report 2005 - Exploring the links between trade, standards and the WTO. Ginebra: autor. 


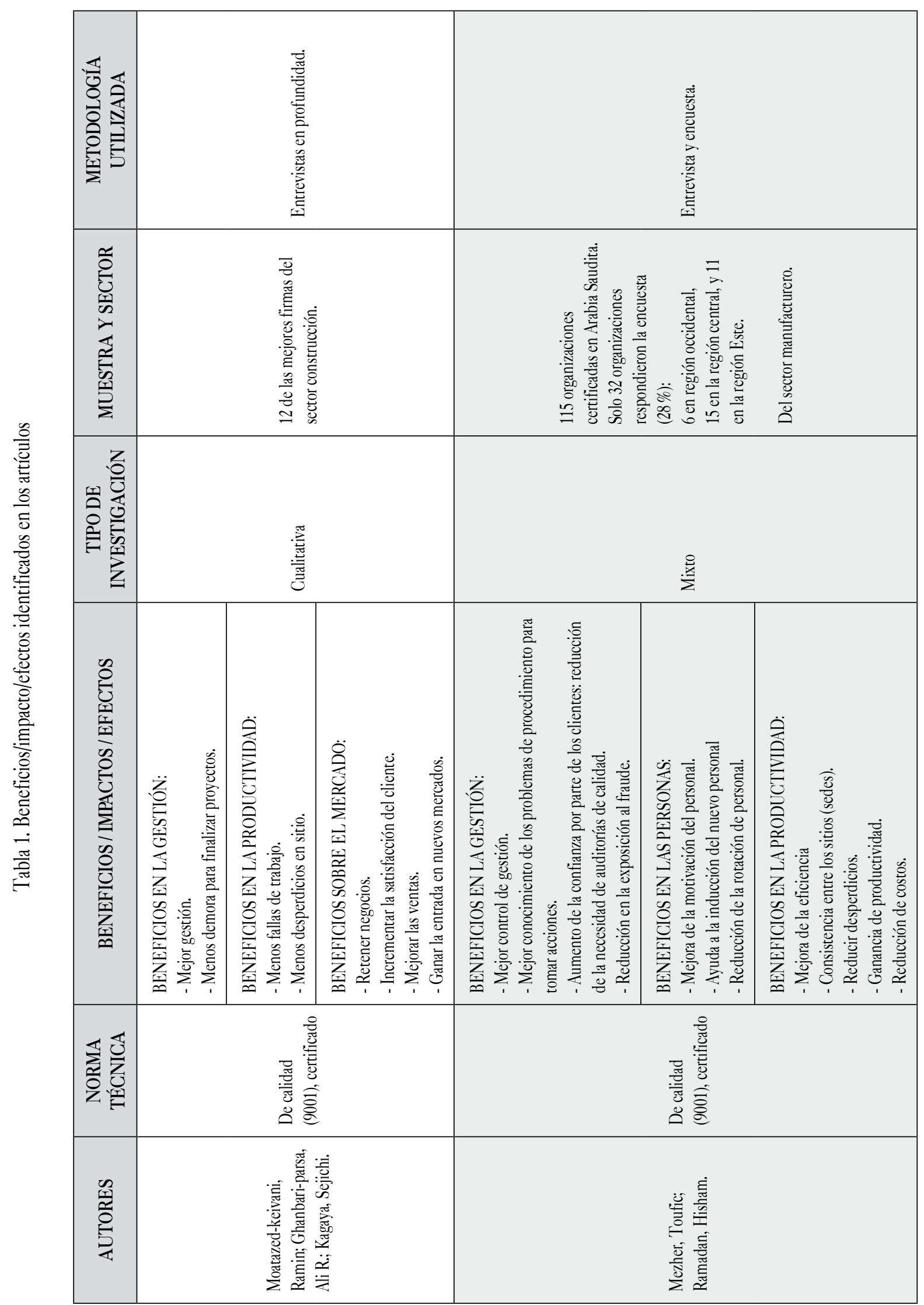




\begin{tabular}{|c|c|c|c|c|c|}
\hline 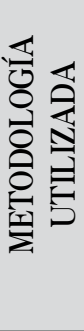 & & & & 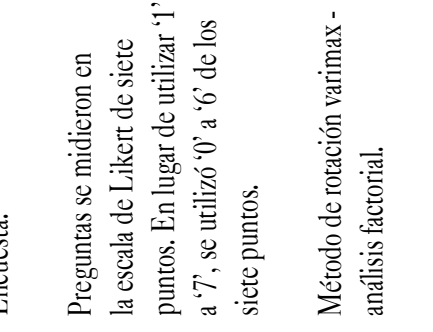 & 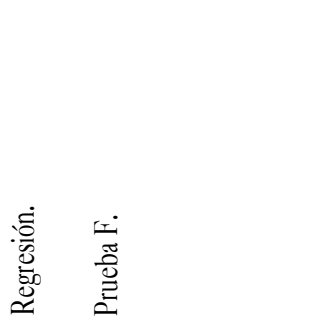 \\
\hline 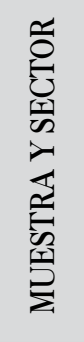 & & \multicolumn{4}{|c|}{ 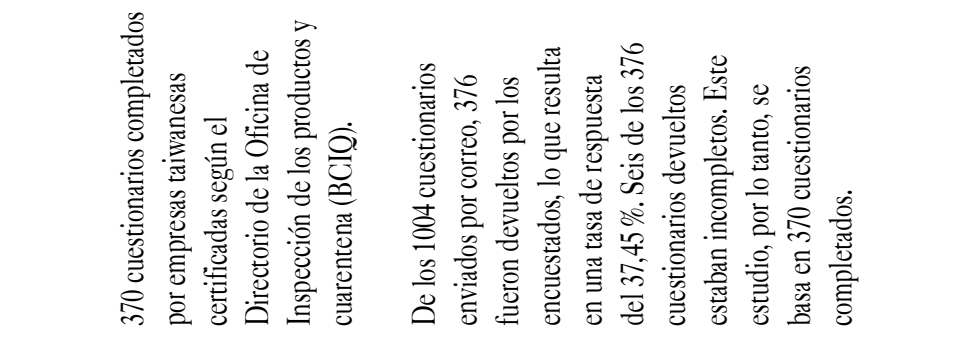 } \\
\hline 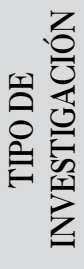 & & \multicolumn{4}{|c|}{ 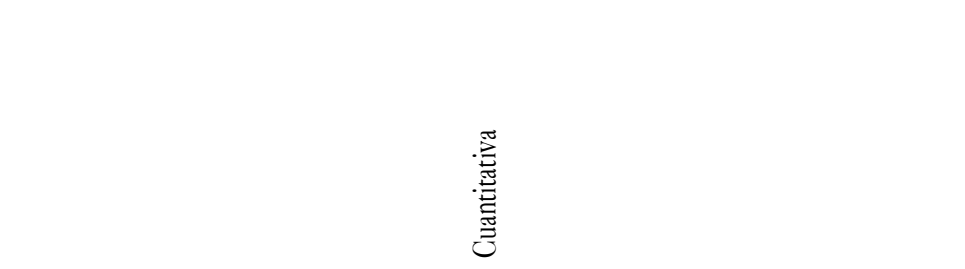 } \\
\hline 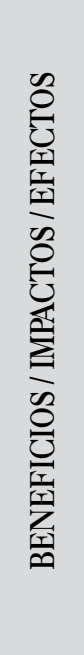 & 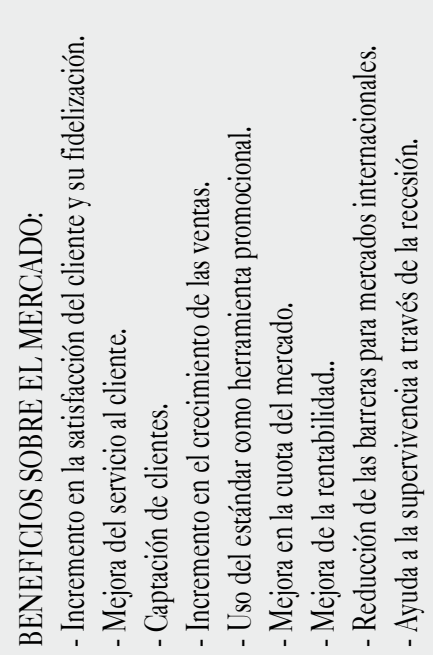 & 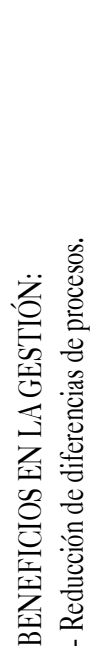 & 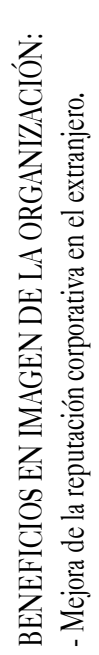 & 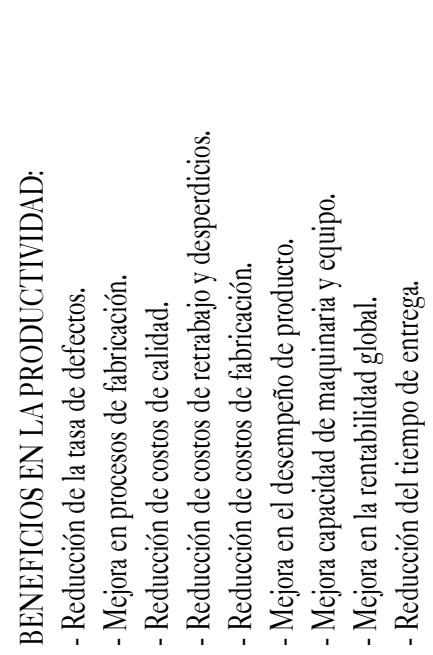 & 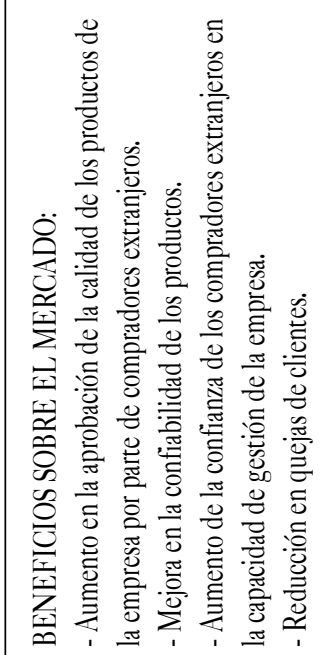 \\
\hline 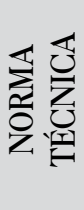 & & \multicolumn{4}{|c|}{ 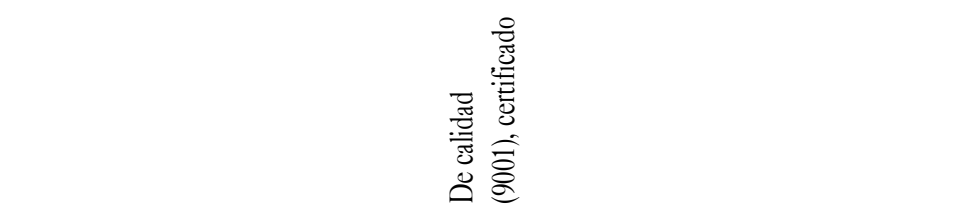 } \\
\hline 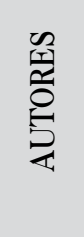 & & \multicolumn{4}{|c|}{ 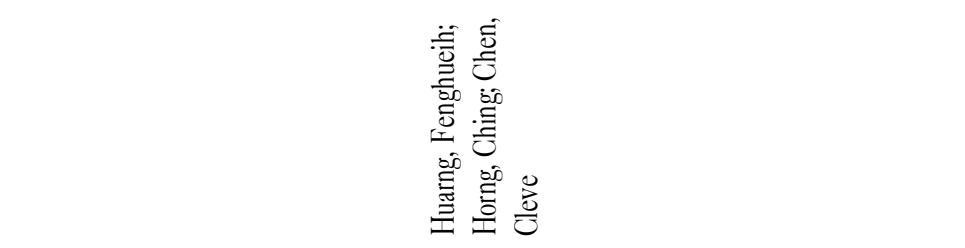 } \\
\hline
\end{tabular}




\begin{tabular}{|c|c|c|c|c|c|c|c|c|}
\hline 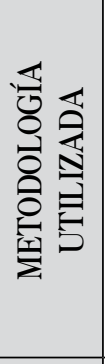 & & & 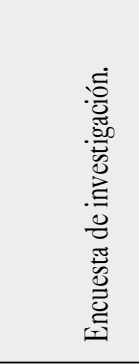 & & \multicolumn{4}{|c|}{ 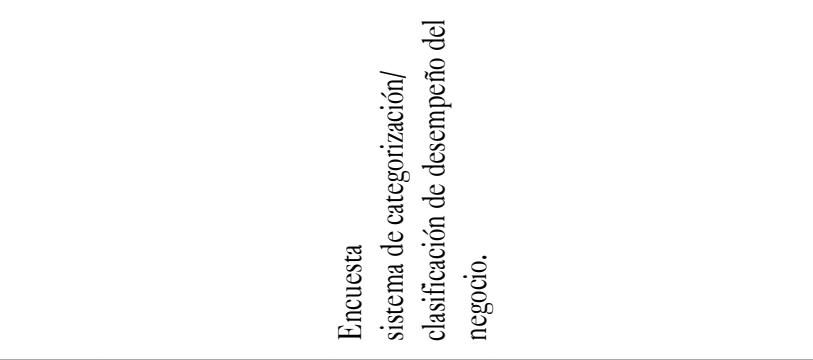 } \\
\hline 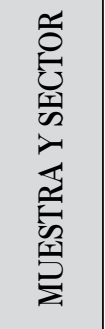 & & \multicolumn{3}{|c|}{ 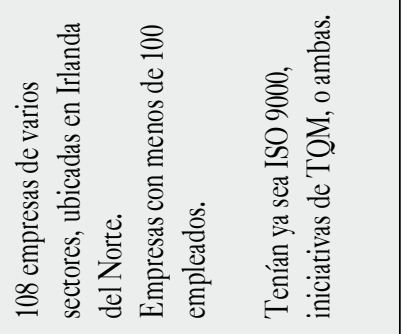 } & \multicolumn{4}{|c|}{ 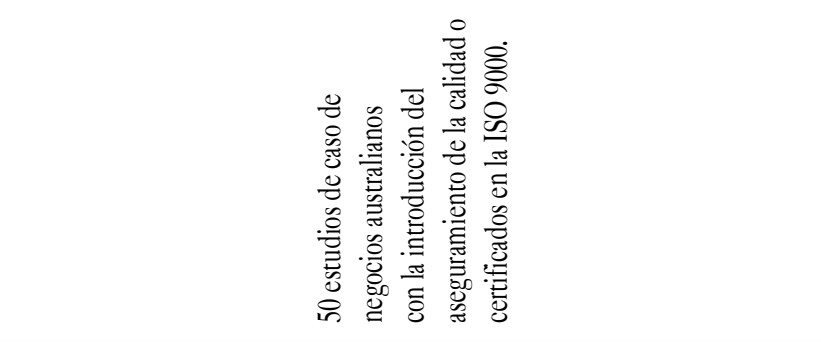 } \\
\hline 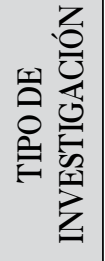 & & \multicolumn{3}{|c|}{ 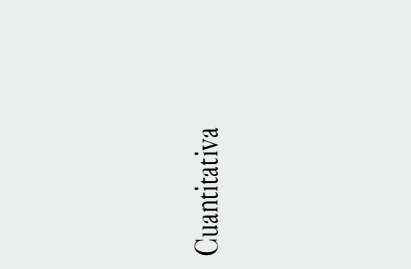 } & \multicolumn{4}{|c|}{ 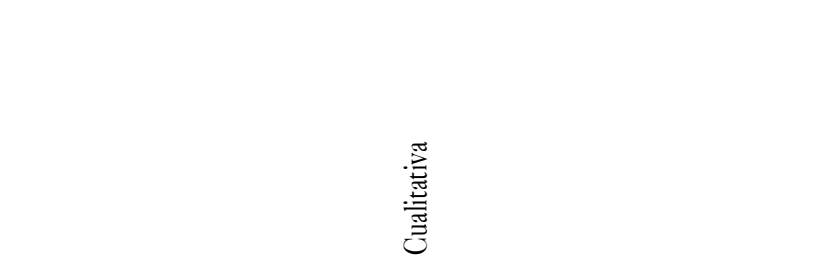 } \\
\hline 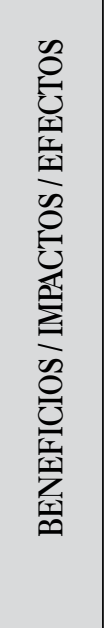 & 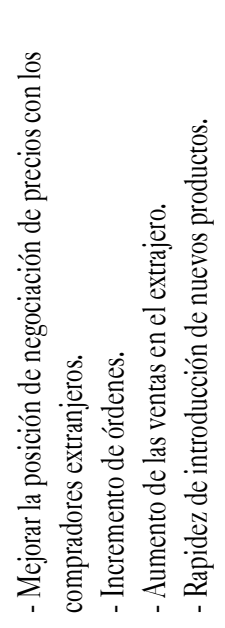 & 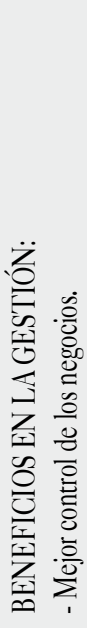 & 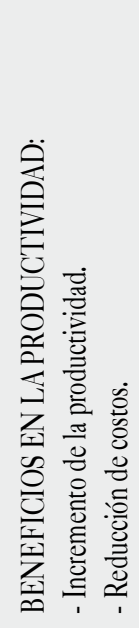 & 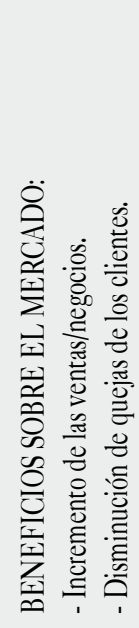 & 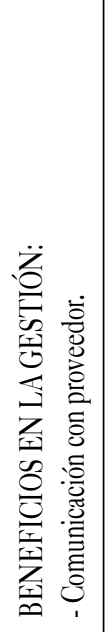 & 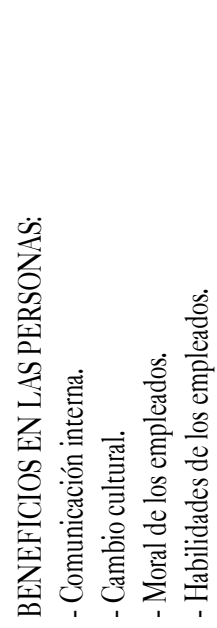 & 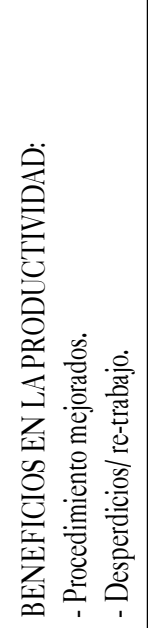 & 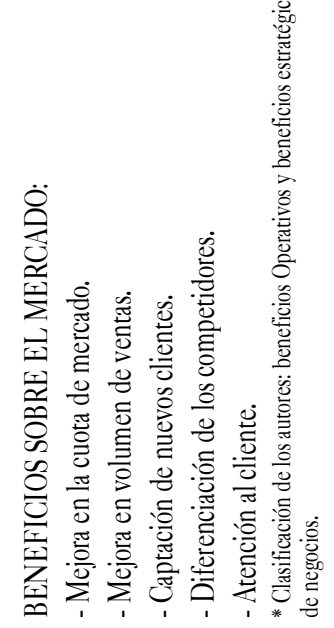 \\
\hline 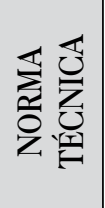 & & \multicolumn{3}{|c|}{ 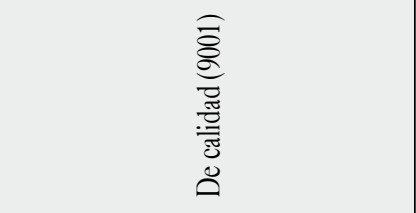 } & \multicolumn{4}{|c|}{ 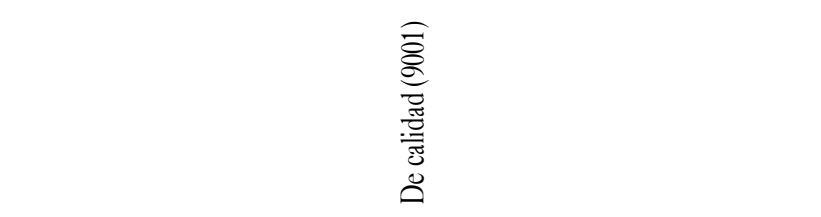 } \\
\hline 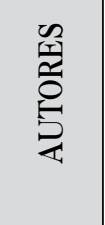 & & \multicolumn{3}{|c|}{ 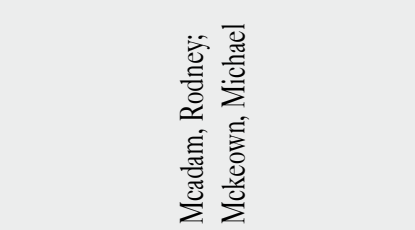 } & \multicolumn{4}{|c|}{ 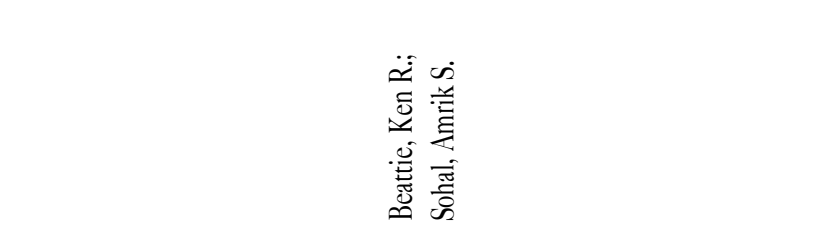 } \\
\hline
\end{tabular}




\begin{tabular}{|c|c|c|c|c|c|c|c|c|}
\hline 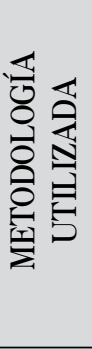 & \multicolumn{3}{|c|}{ 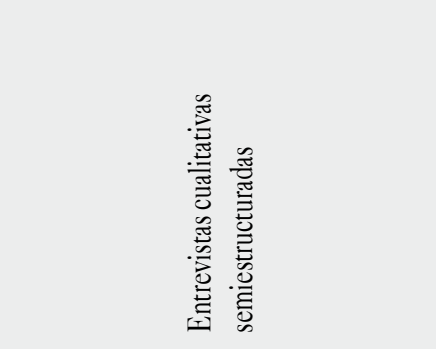 } & 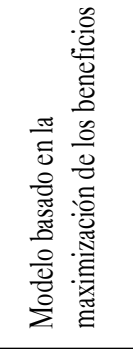 & 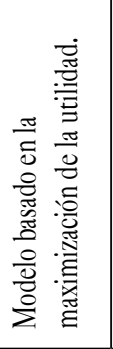 & \multicolumn{3}{|c|}{ 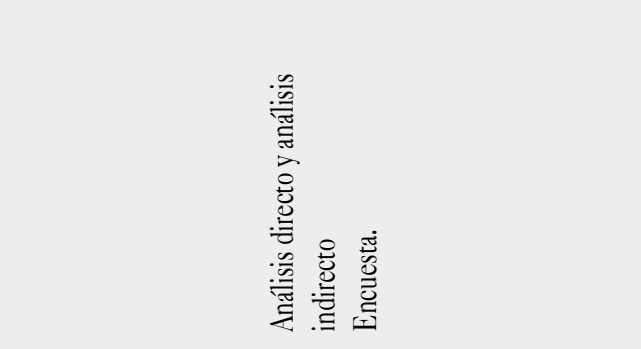 } \\
\hline 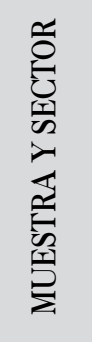 & \multicolumn{3}{|c|}{ 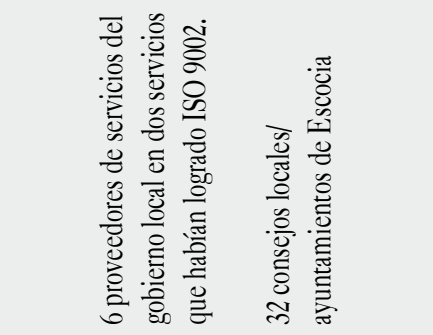 } & \multicolumn{2}{|c|}{ 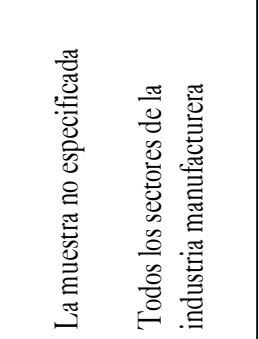 } & \multicolumn{3}{|c|}{ 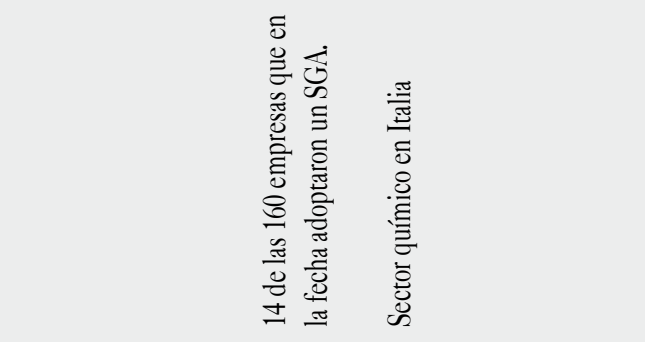 } \\
\hline 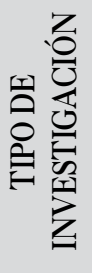 & \multicolumn{3}{|c|}{ 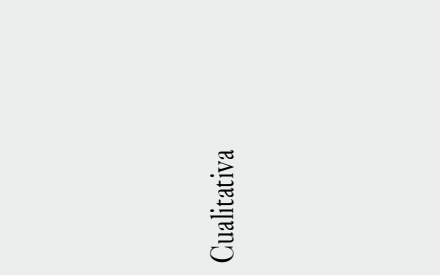 } & \multicolumn{2}{|c|}{ 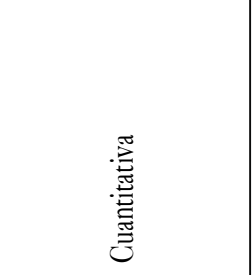 } & \multicolumn{3}{|l|}{ 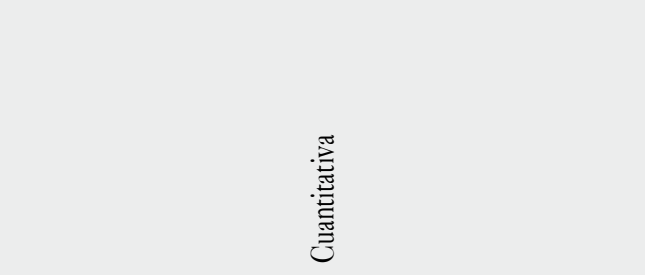 } \\
\hline 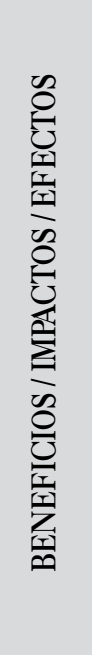 & 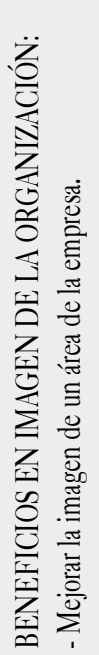 & 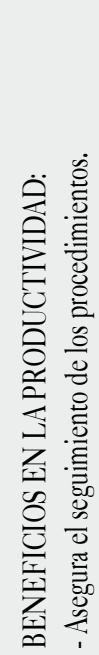 & 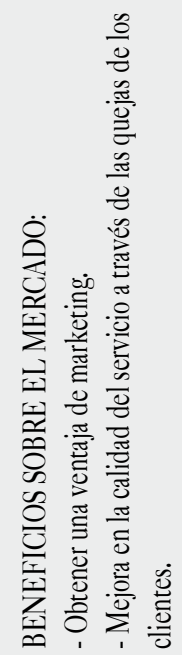 & 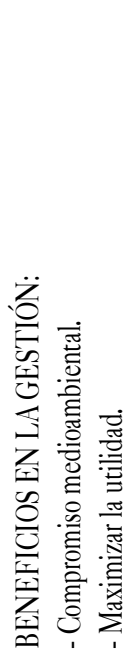 & 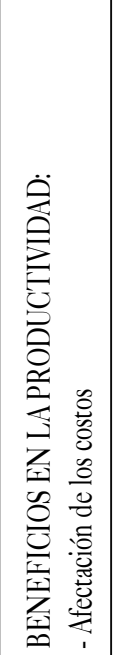 & 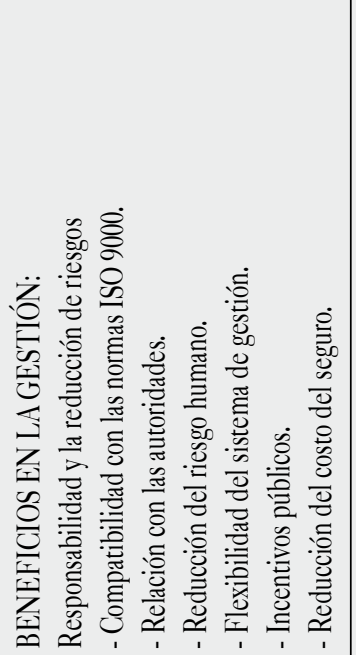 & 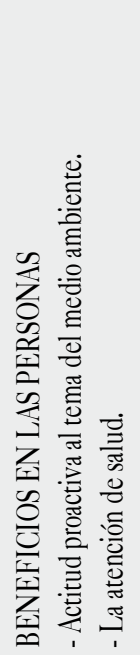 & 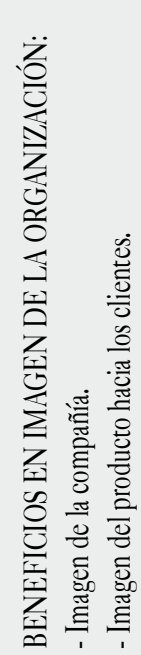 \\
\hline 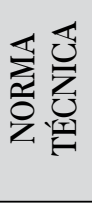 & \multicolumn{3}{|c|}{ 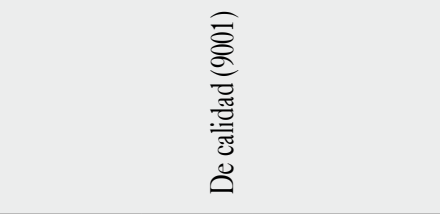 } & \multicolumn{2}{|c|}{ 焉 } & \multicolumn{3}{|c|}{ 焉 } \\
\hline 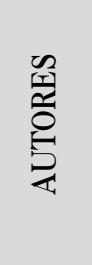 & \multicolumn{3}{|c|}{ 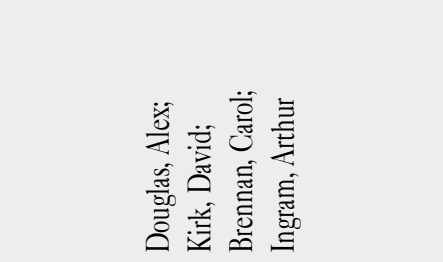 } & \multicolumn{2}{|c|}{ 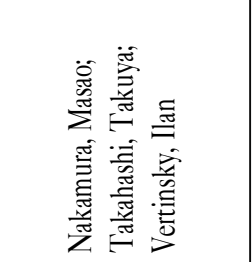 } & \multicolumn{3}{|c|}{ 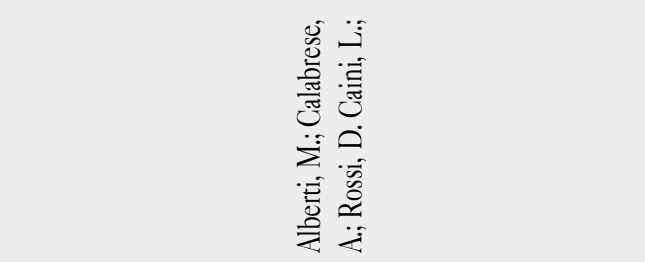 } \\
\hline
\end{tabular}




\begin{tabular}{|c|c|c|c|c|c|}
\hline 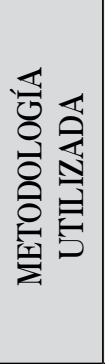 & & & 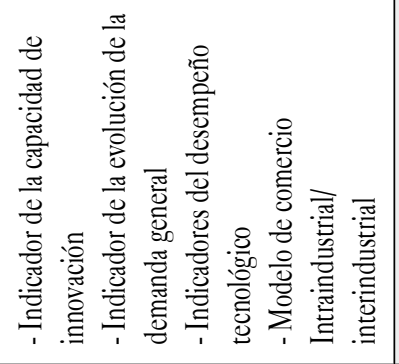 & 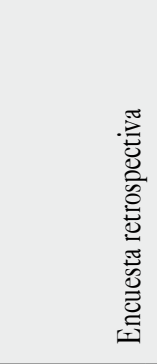 & \\
\hline 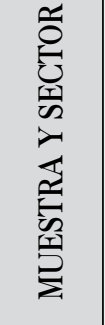 & & & 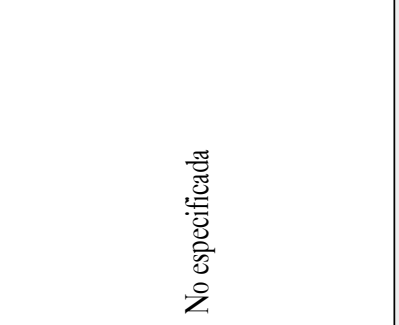 & 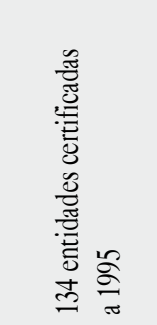 & 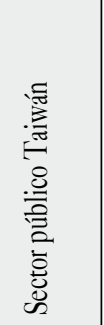 \\
\hline 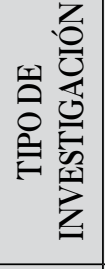 & & & 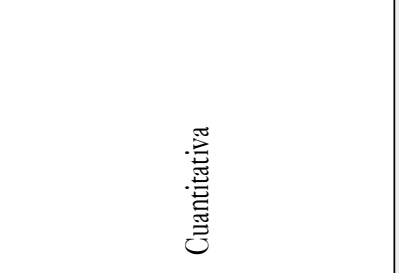 & 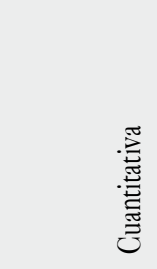 & \\
\hline 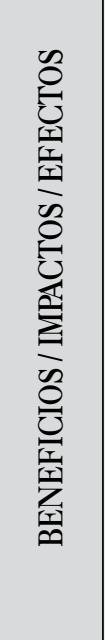 & 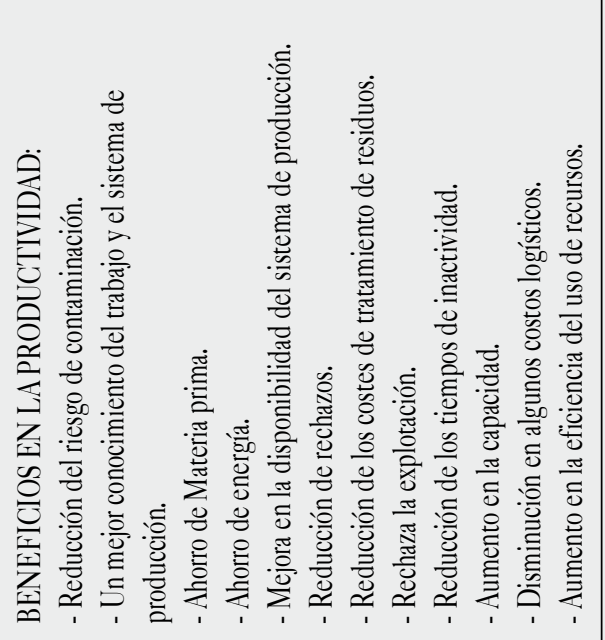 & 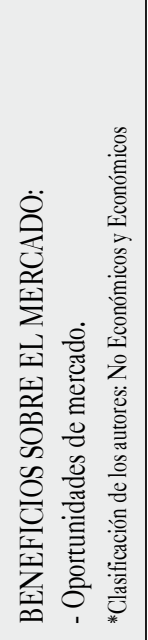 & 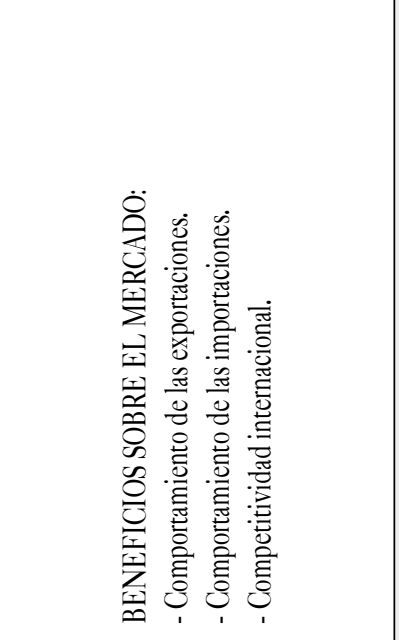 & 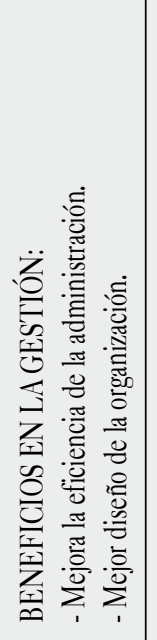 & 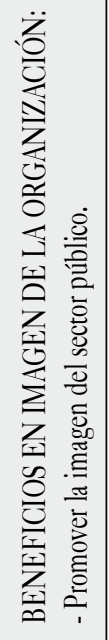 \\
\hline 焉岂 & & & 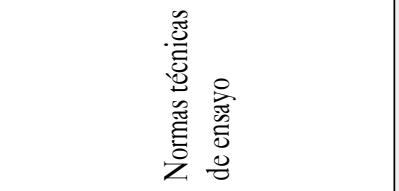 & 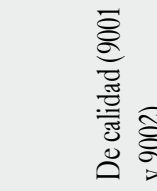 & \\
\hline 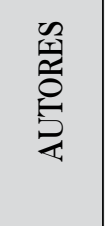 & & & 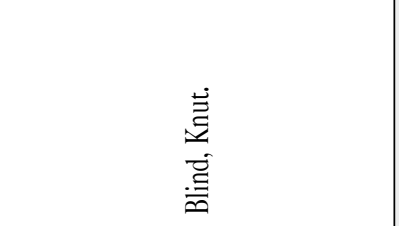 & 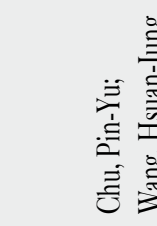 & \\
\hline
\end{tabular}




\begin{tabular}{|c|c|c|c|c|c|c|c|c|}
\hline 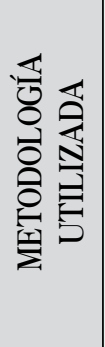 & & & \multicolumn{4}{|c|}{ 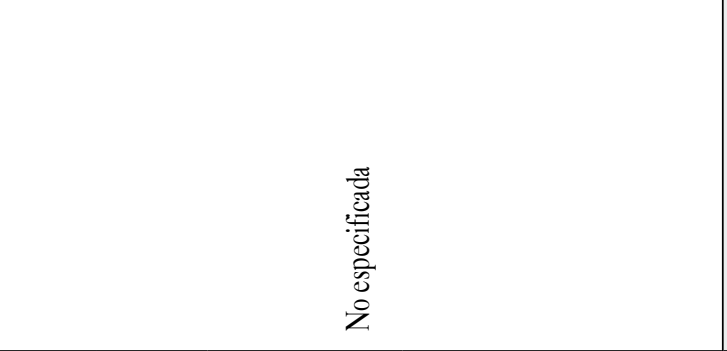 } & 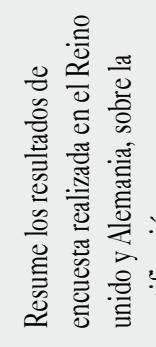 & 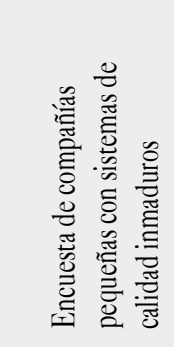 \\
\hline 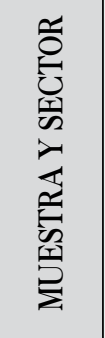 & & & \multicolumn{4}{|c|}{ 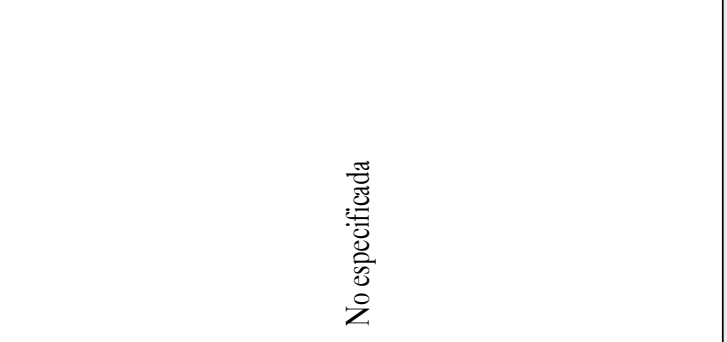 } & \multicolumn{2}{|c|}{ 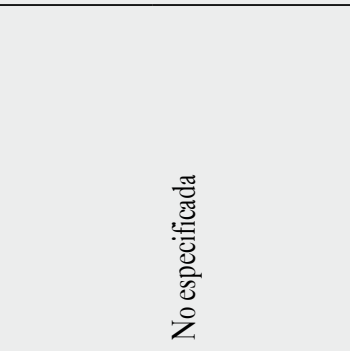 } \\
\hline 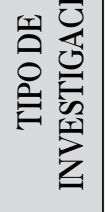 & & & \multicolumn{4}{|c|}{ 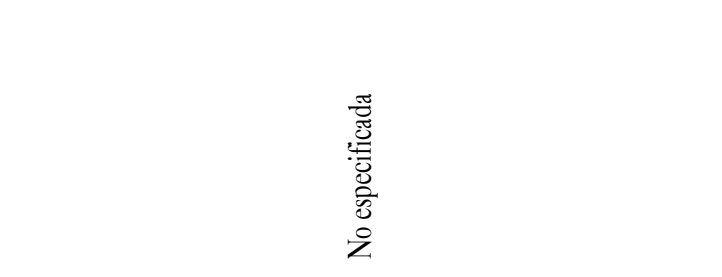 } & \multicolumn{2}{|c|}{ 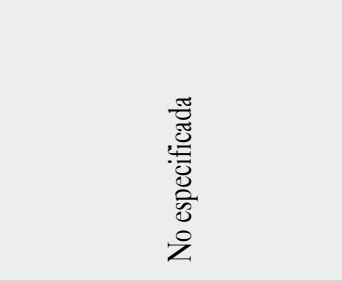 } \\
\hline 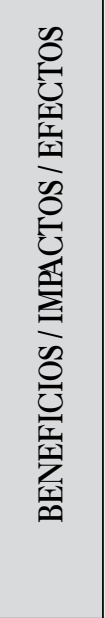 & 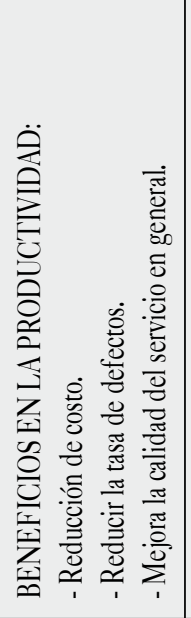 & 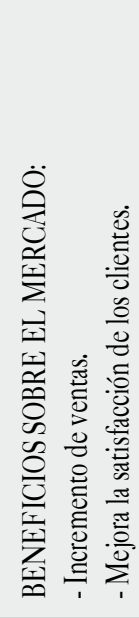 & 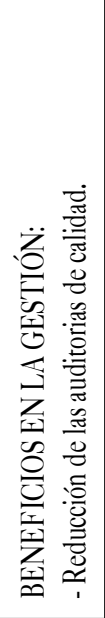 & 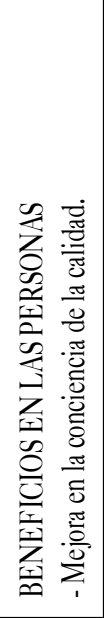 & 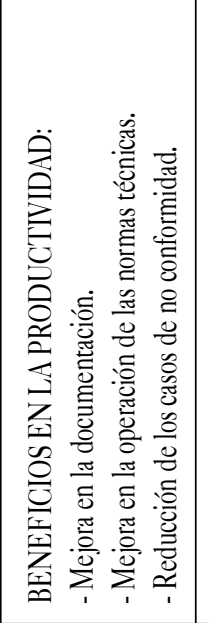 & 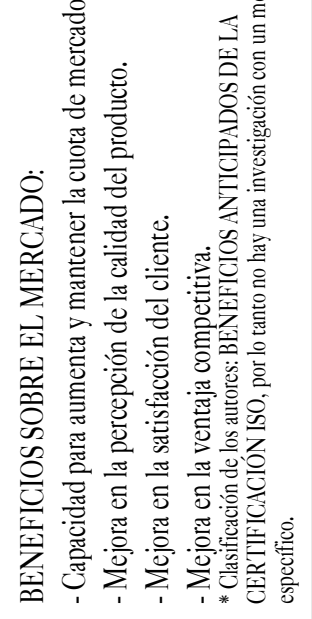 & 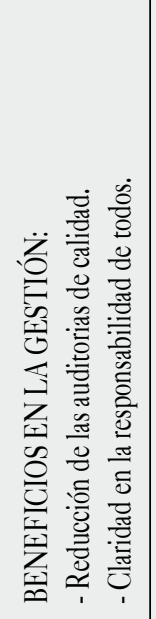 & 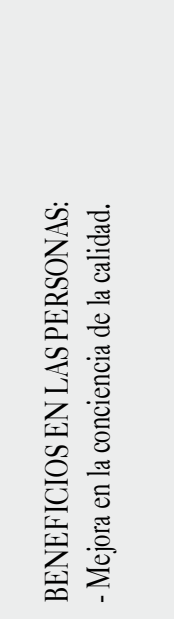 \\
\hline 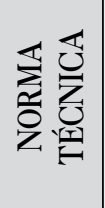 & & & \multicolumn{4}{|c|}{ 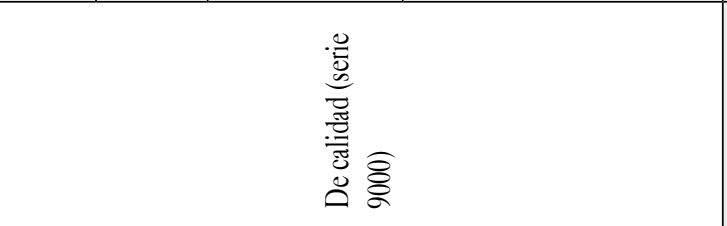 } & \multicolumn{2}{|c|}{ 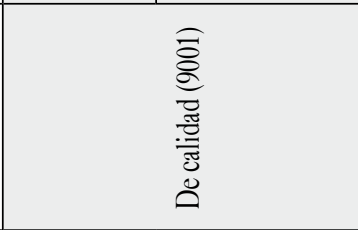 } \\
\hline 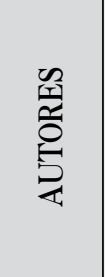 & & & \multicolumn{4}{|c|}{ 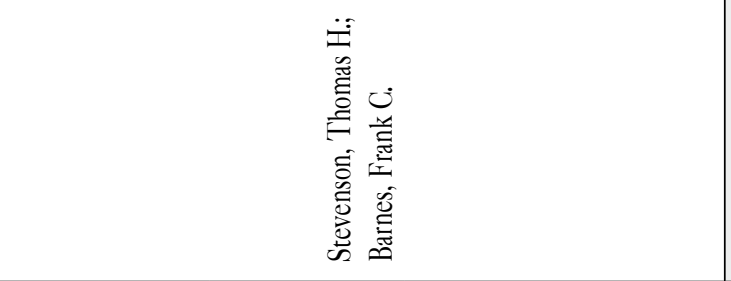 } & \multicolumn{2}{|c|}{ 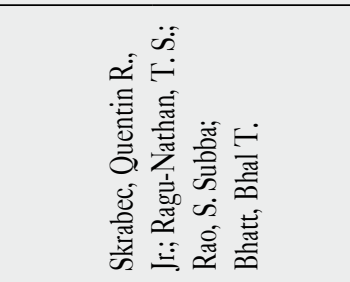 } \\
\hline
\end{tabular}




\begin{tabular}{|c|c|c|c|c|c|c|}
\hline 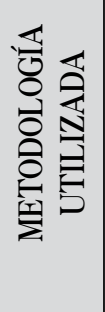 & & & & 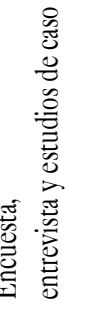 & & \\
\hline 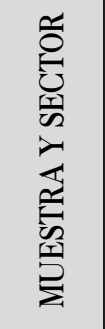 & & & \multicolumn{4}{|c|}{ 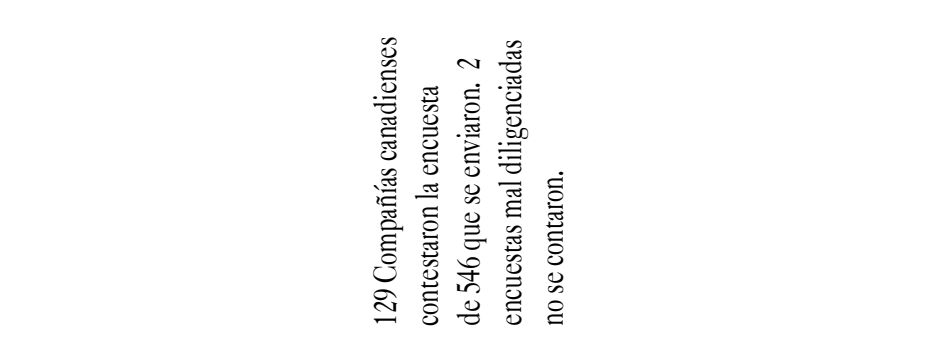 } \\
\hline 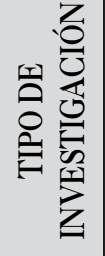 & & & \multicolumn{4}{|c|}{ 章 } \\
\hline 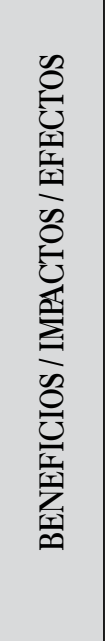 & 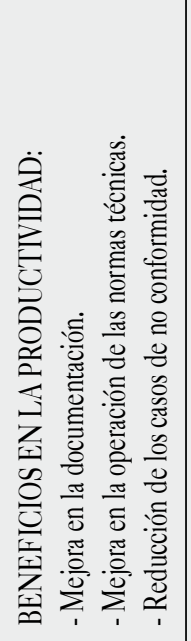 & 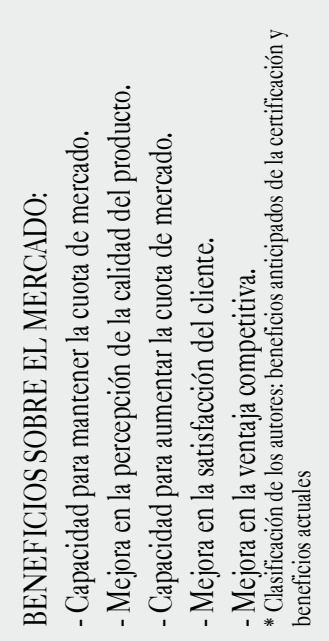 & 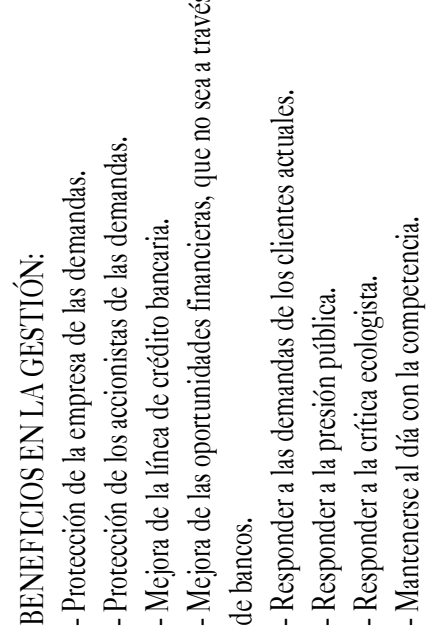 & 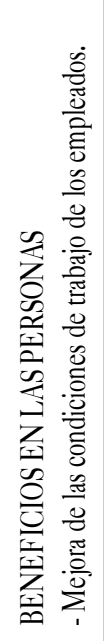 & 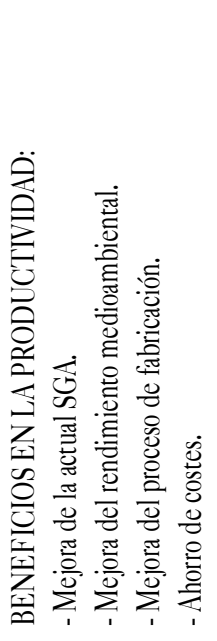 & 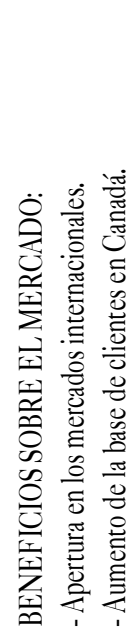 \\
\hline 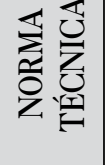 & & & \multicolumn{4}{|c|}{ 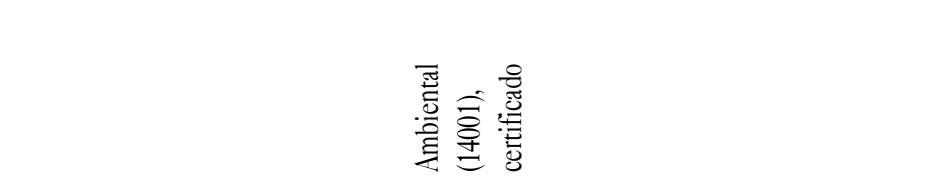 } \\
\hline 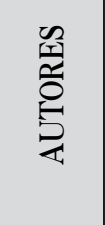 & & & \multicolumn{4}{|c|}{ 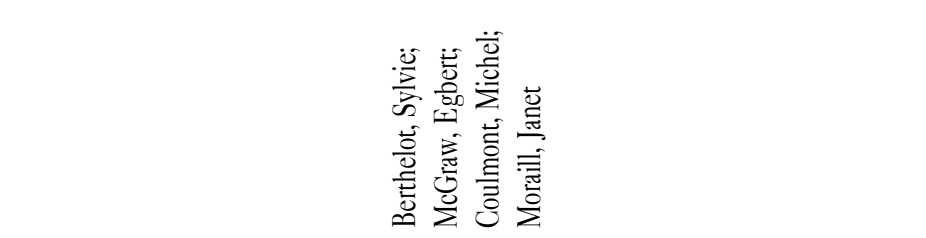 } \\
\hline
\end{tabular}


Constanza Cristina Díaz Romero, Yuber Liliana Rodríguez-Rojas

\begin{tabular}{|c|c|c|c|c|c|c|c|c|}
\hline 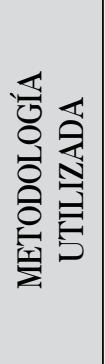 & \multicolumn{2}{|c|}{ 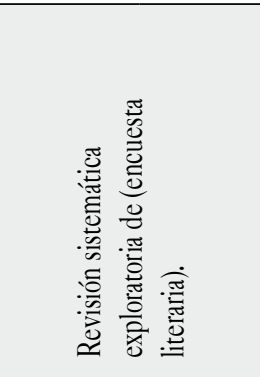 } & \multicolumn{4}{|c|}{ 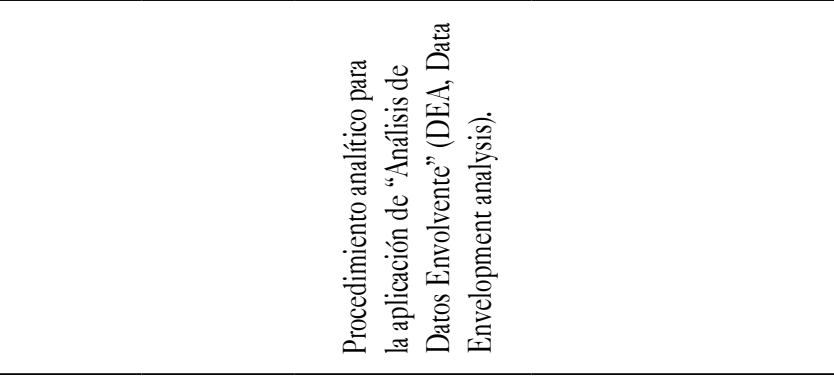 } & \multicolumn{2}{|c|}{ 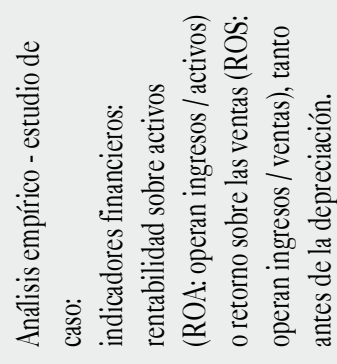 } \\
\hline 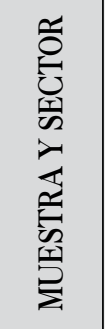 & \multicolumn{2}{|c|}{ 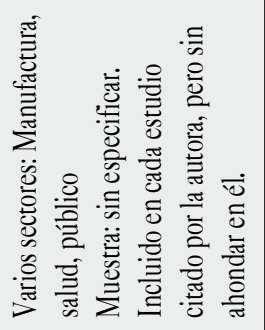 } & \multicolumn{4}{|c|}{ 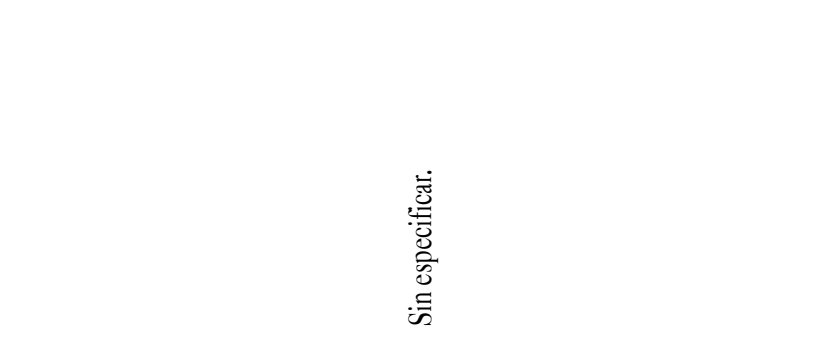 } & \multicolumn{2}{|r|}{ 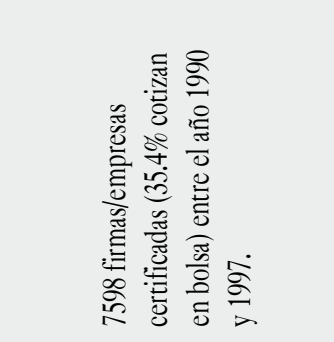 } \\
\hline 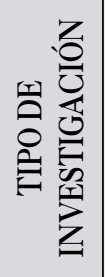 & \multicolumn{2}{|c|}{ 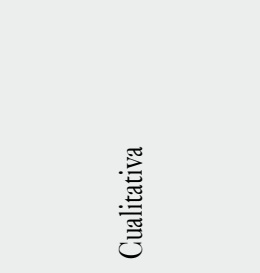 } & \multicolumn{4}{|c|}{ 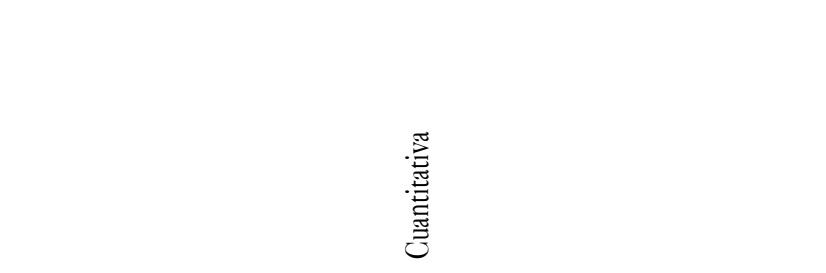 } & \multicolumn{2}{|r|}{ 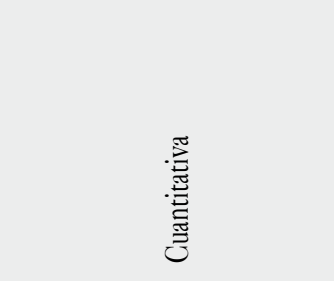 } \\
\hline 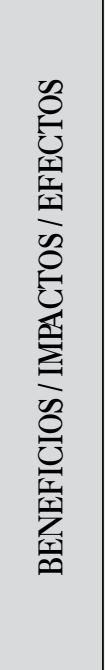 & 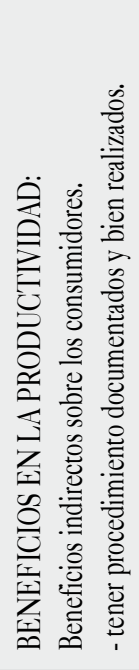 & 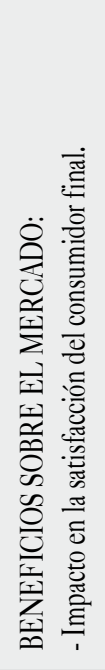 & 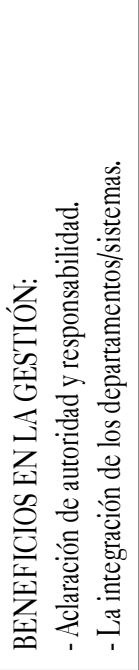 & 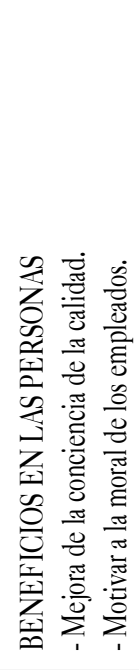 & 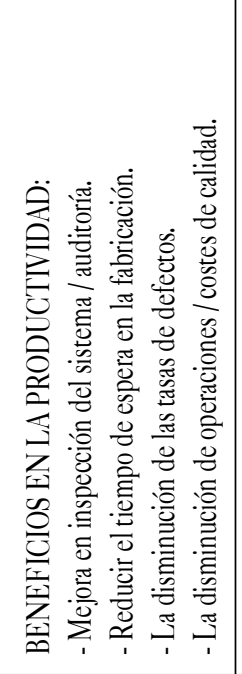 & 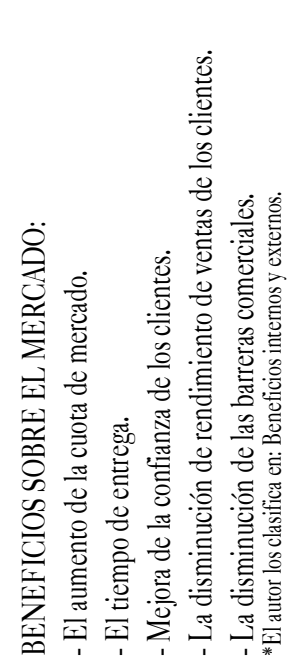 & 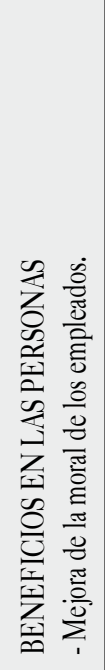 & 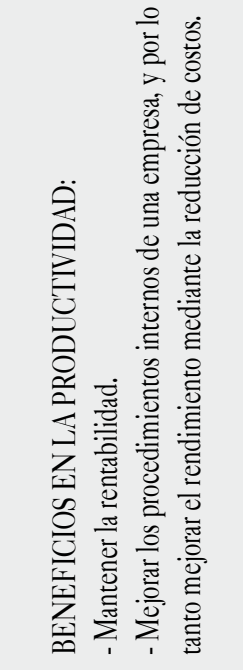 \\
\hline 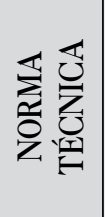 & \multicolumn{2}{|c|}{ 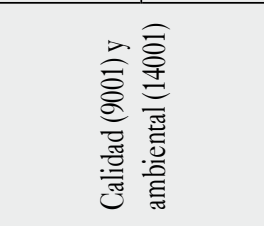 } & \multicolumn{4}{|c|}{ 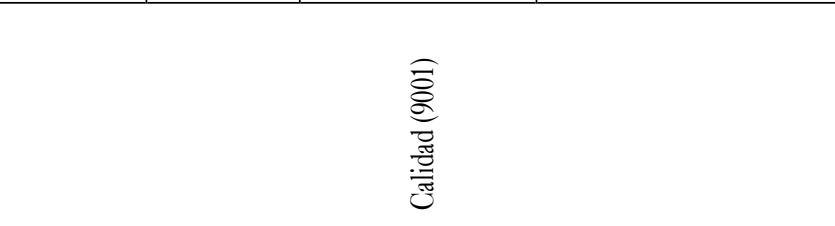 } & \multicolumn{2}{|r|}{ 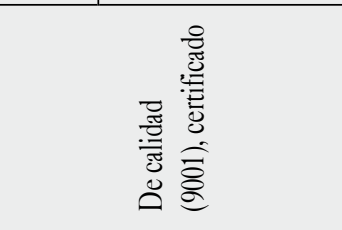 } \\
\hline 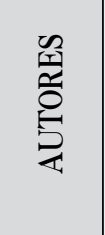 & \multicolumn{2}{|c|}{ 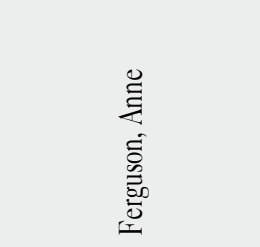 } & \multicolumn{4}{|c|}{ 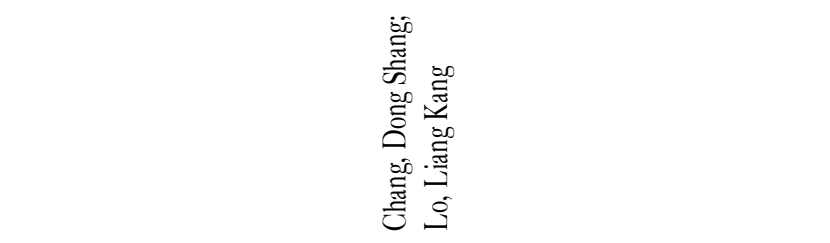 } & \multicolumn{2}{|c|}{ 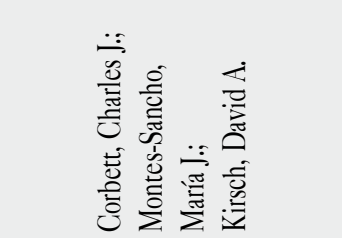 } \\
\hline
\end{tabular}




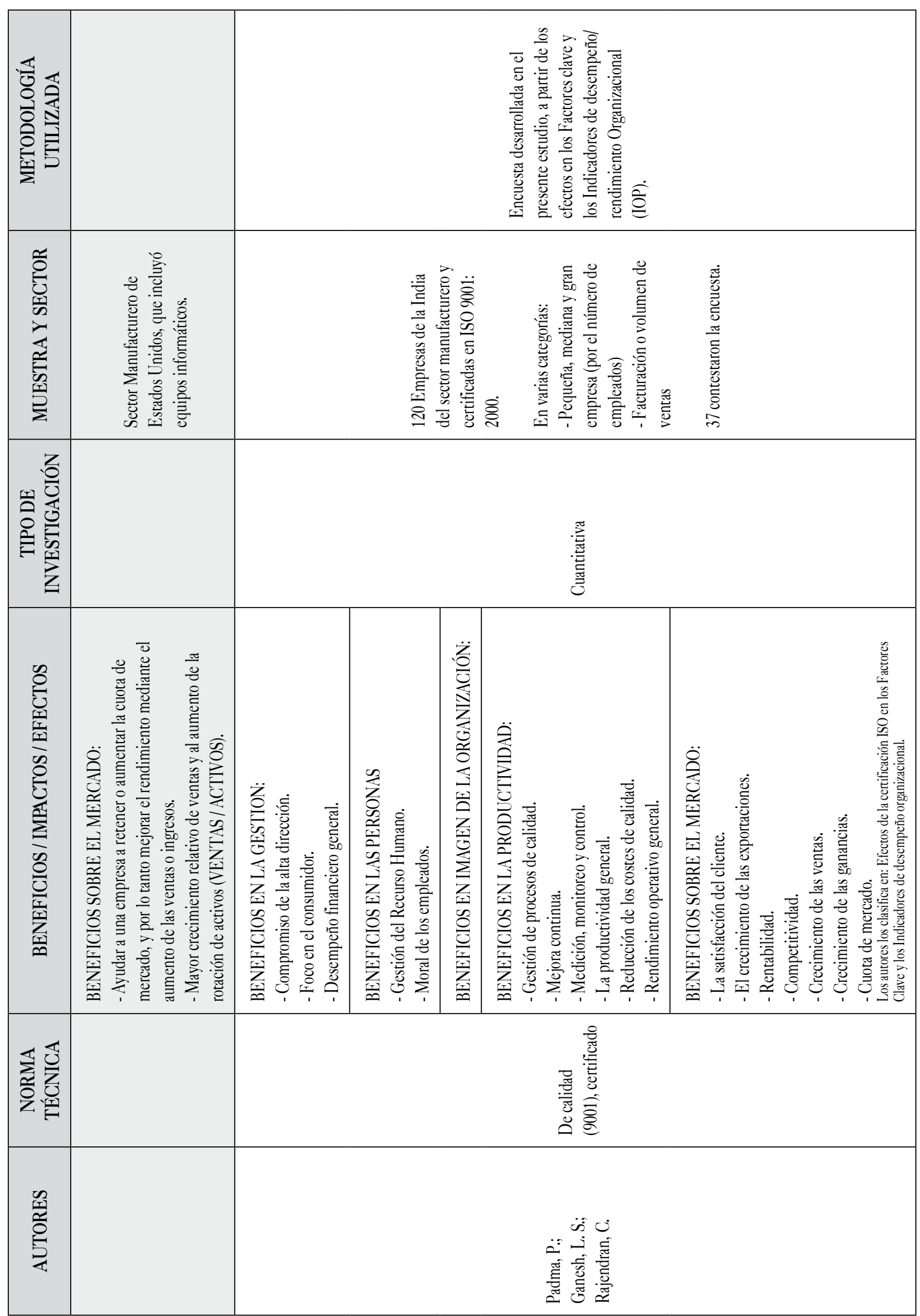




\begin{tabular}{|c|c|c|c|c|c|c|c|}
\hline 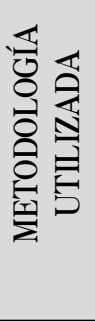 & \multicolumn{5}{|c|}{ 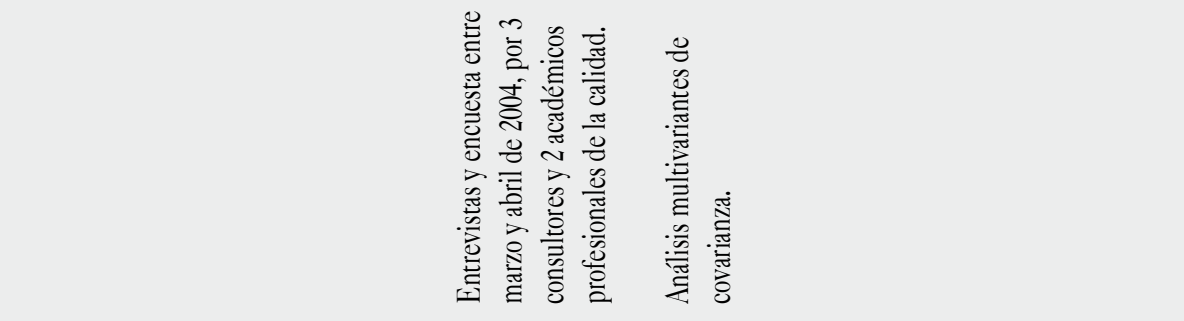 } & & 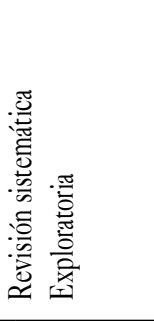 \\
\hline 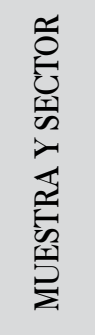 & \multicolumn{5}{|c|}{ 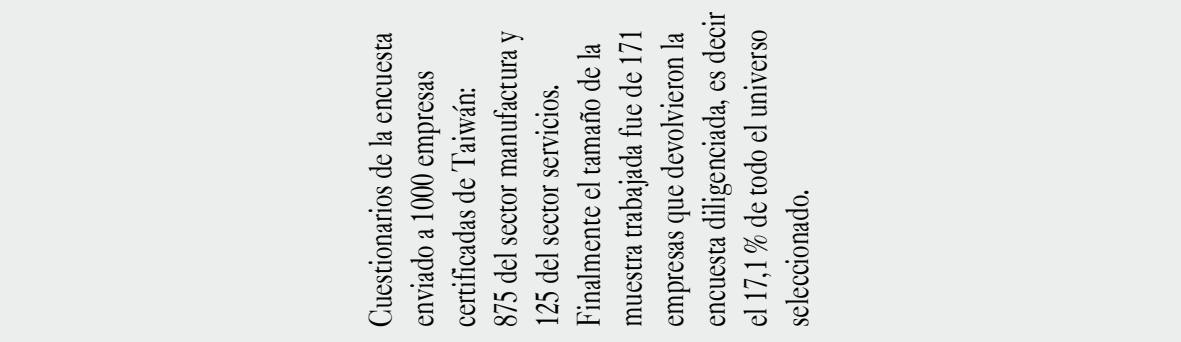 } & \multirow{2}{*}{\multicolumn{2}{|c|}{ 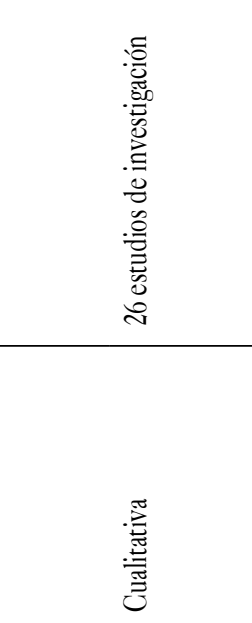 }} \\
\hline 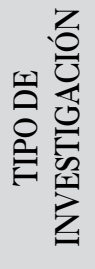 & \multicolumn{5}{|c|}{ 晃 } & & \\
\hline 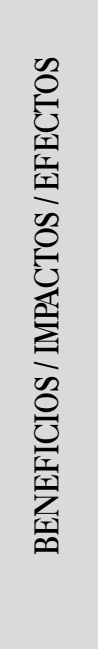 & 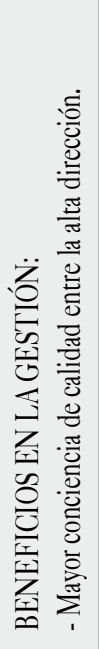 & 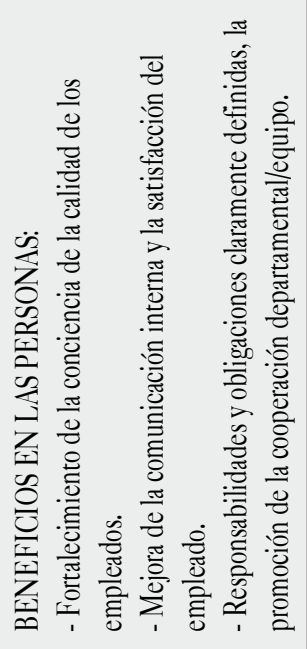 & 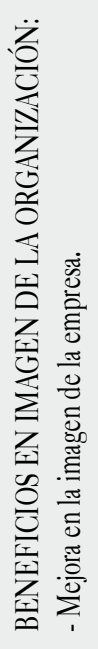 & 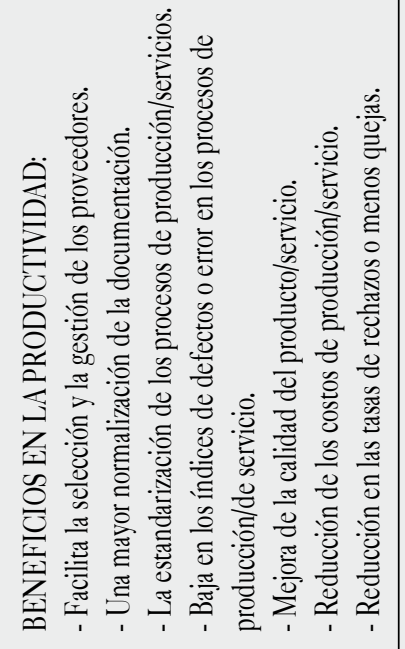 & 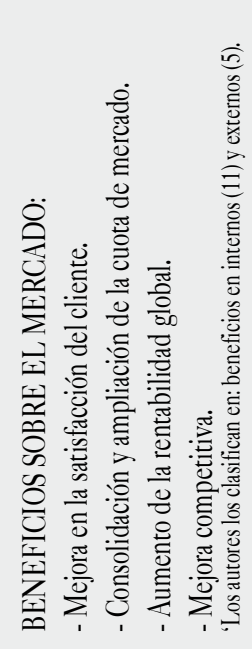 & 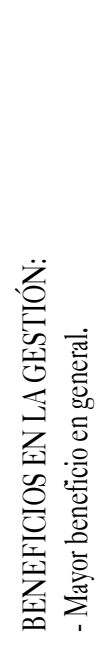 & 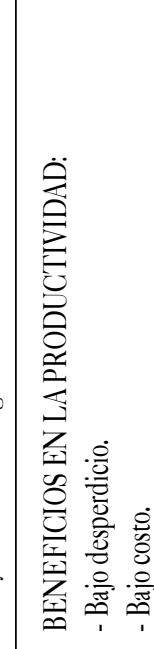 \\
\hline 壳岕 & \multicolumn{5}{|c|}{ 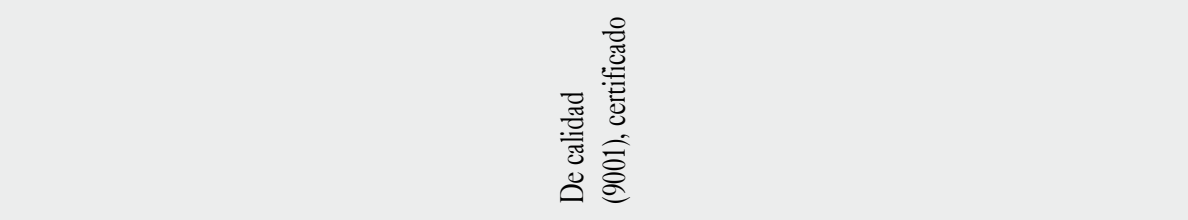 } & \multicolumn{2}{|c|}{ 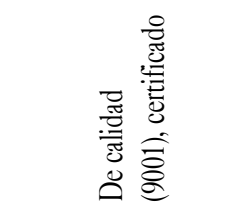 } \\
\hline 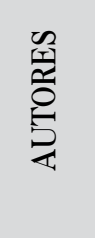 & \multicolumn{5}{|c|}{ 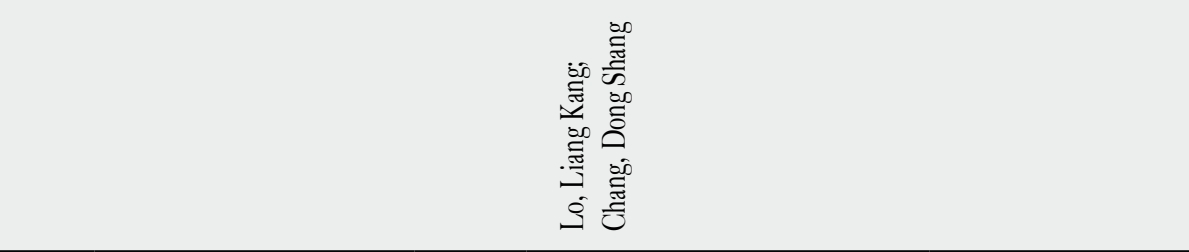 } & & 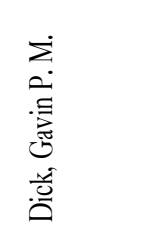 \\
\hline
\end{tabular}




\begin{tabular}{|c|c|c|c|c|c|c|c|c|c|c|c|}
\hline 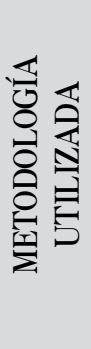 & & & 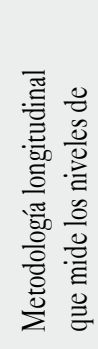 & 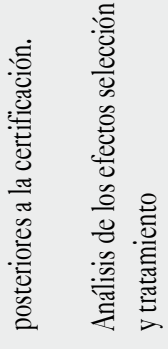 & & 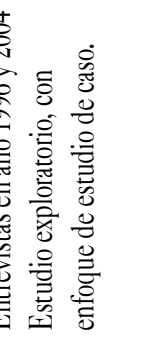 & & \multicolumn{4}{|c|}{ 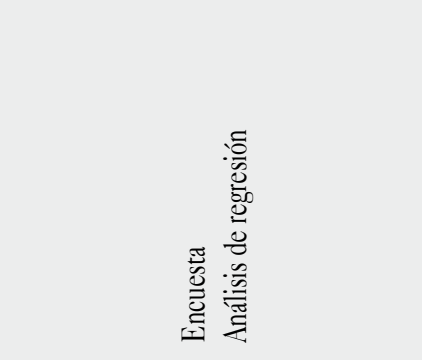 } \\
\hline 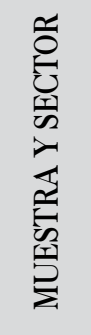 & & & \multicolumn{2}{|c|}{ 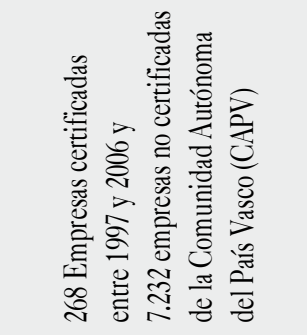 } & \multicolumn{3}{|c|}{ 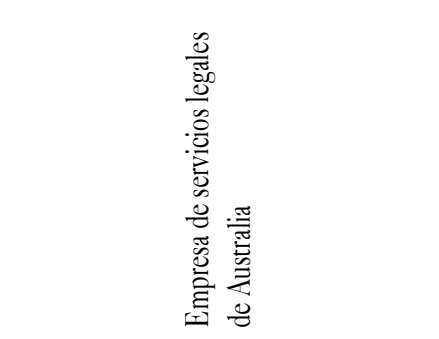 } & \multicolumn{4}{|c|}{ 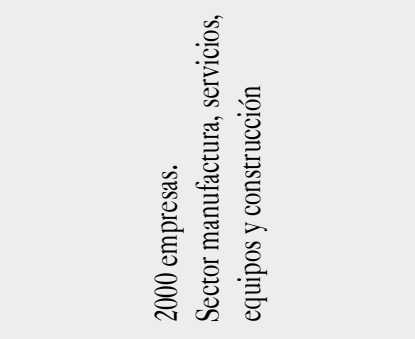 } \\
\hline 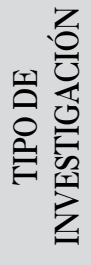 & & & \multicolumn{2}{|r|}{ 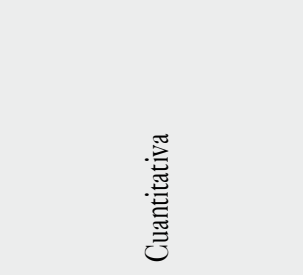 } & \multicolumn{3}{|c|}{ 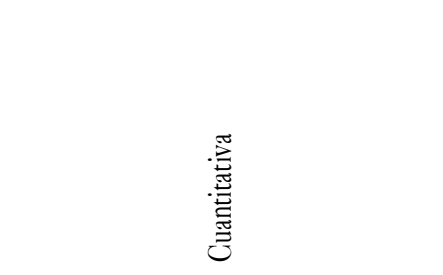 } & \multicolumn{4}{|c|}{ 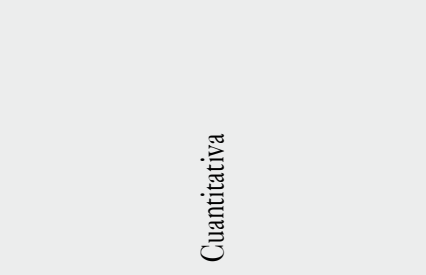 } \\
\hline 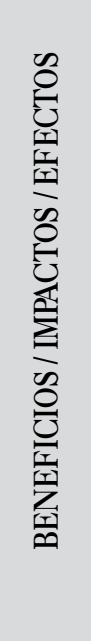 & 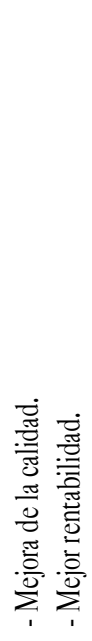 & 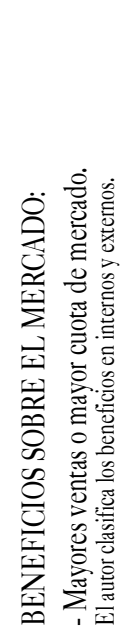 & 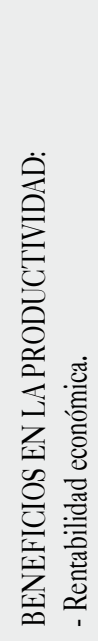 & 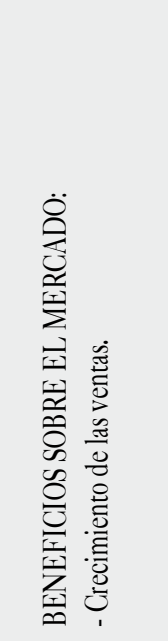 & 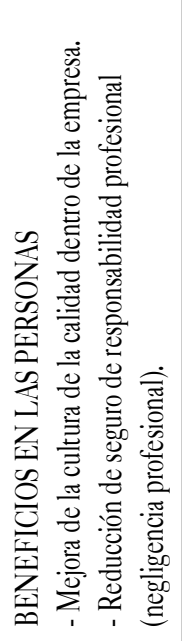 & 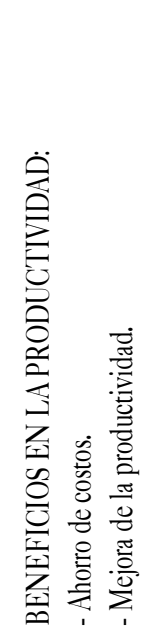 & 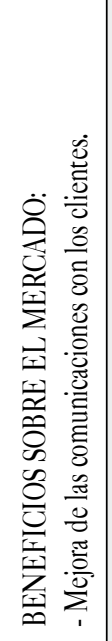 & 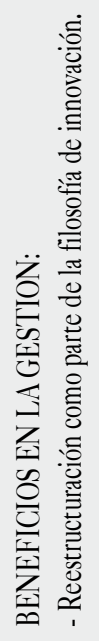 & 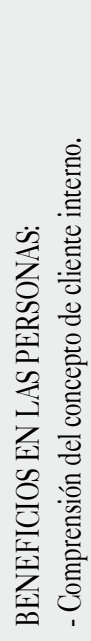 & 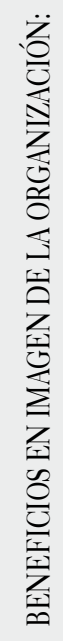 & 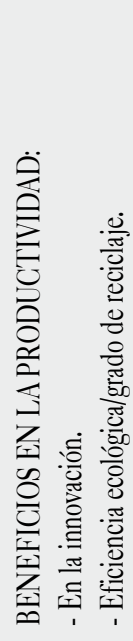 \\
\hline 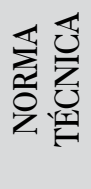 & & & & 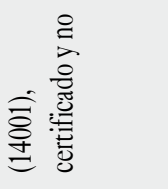 & \multicolumn{3}{|c|}{ 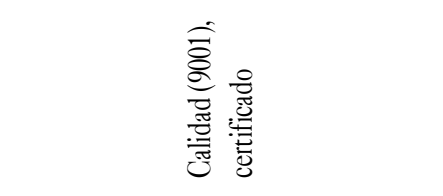 } & \multicolumn{4}{|c|}{ 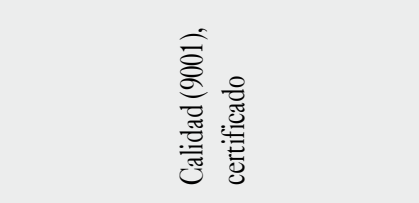 } \\
\hline 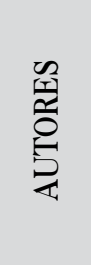 & & & & 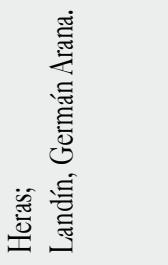 & \multicolumn{3}{|c|}{ 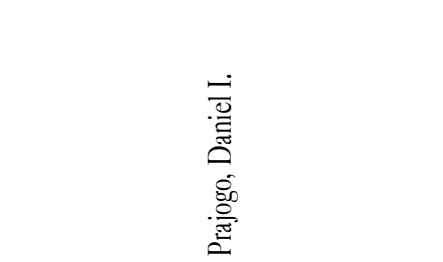 } & \multicolumn{4}{|c|}{ 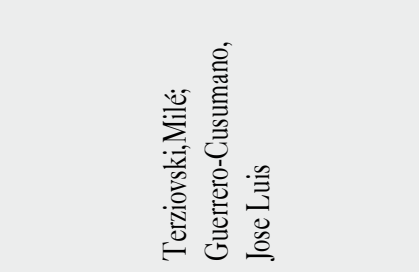 } \\
\hline
\end{tabular}




\begin{tabular}{|c|c|c|c|c|c|}
\hline 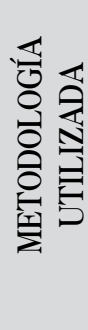 & & \multicolumn{3}{|c|}{ 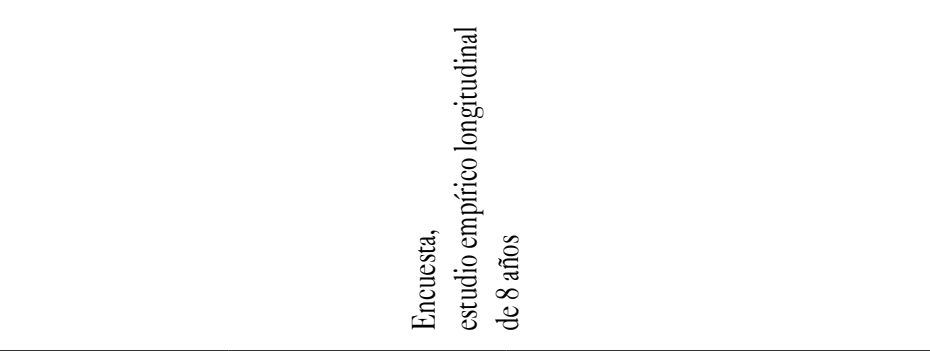 } & 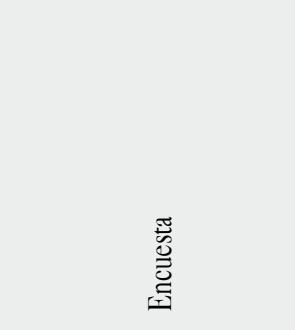 \\
\hline 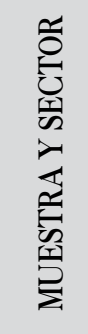 & & \multicolumn{3}{|c|}{ 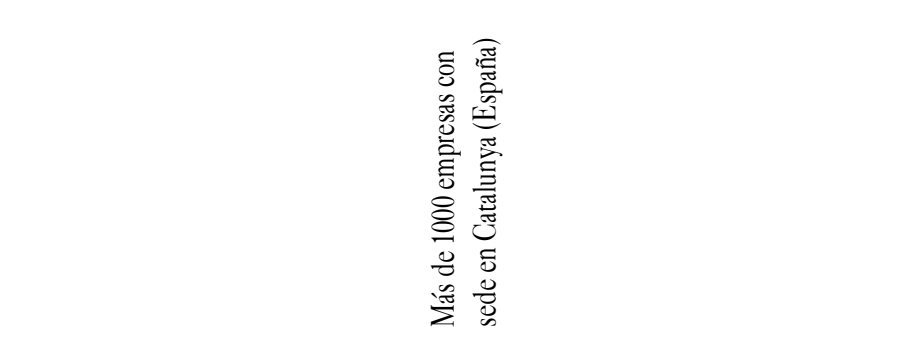 } & 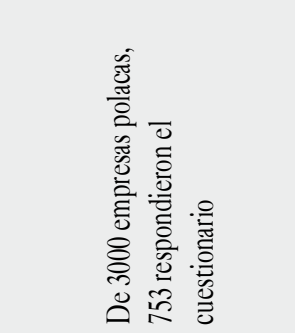 \\
\hline 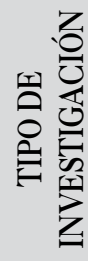 & & \multicolumn{3}{|c|}{ 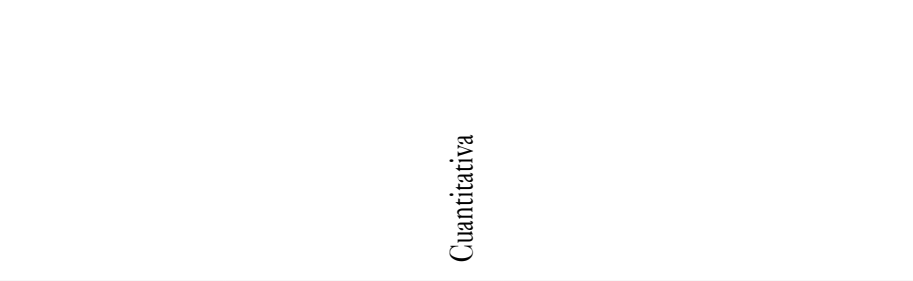 } & 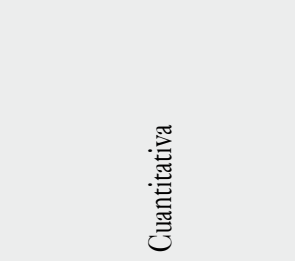 \\
\hline 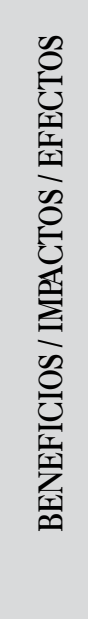 & 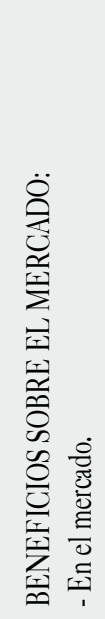 & 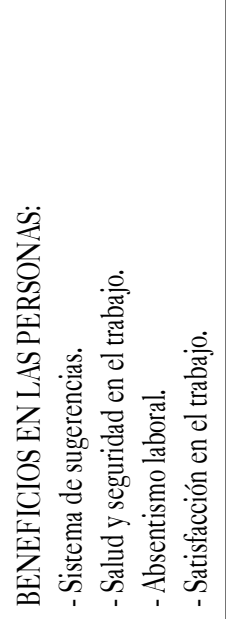 & 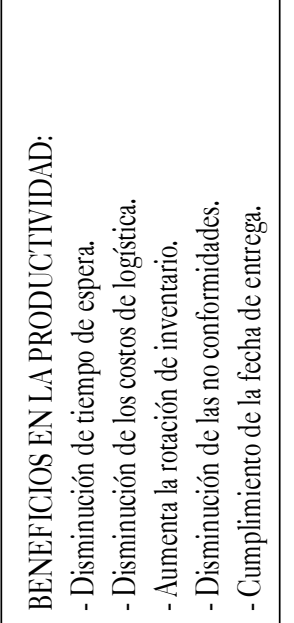 & 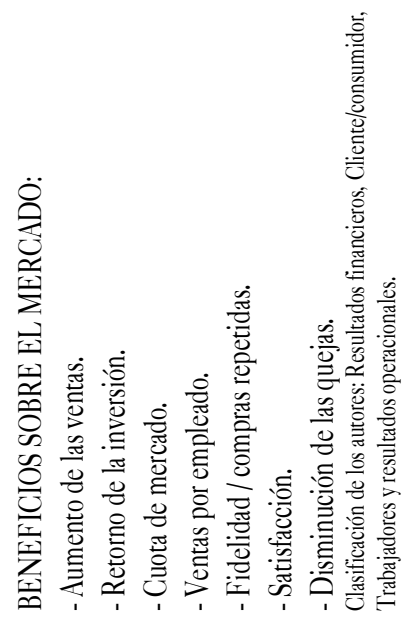 & 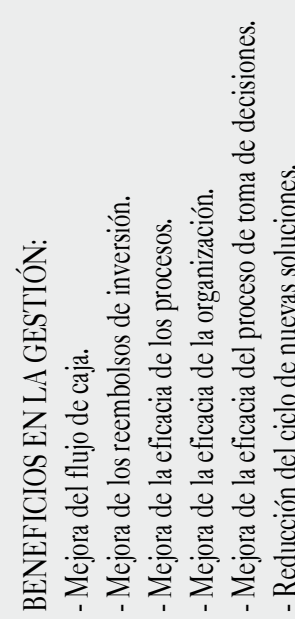 \\
\hline 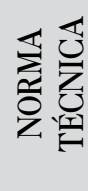 & & \multicolumn{3}{|c|}{ 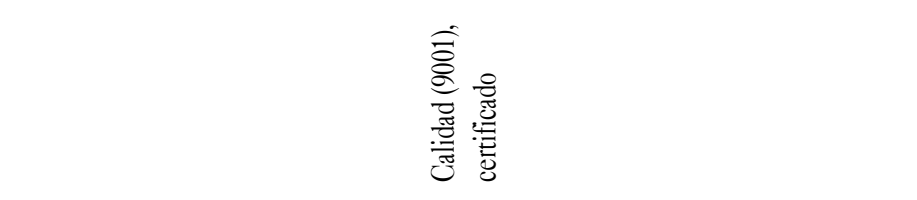 } & 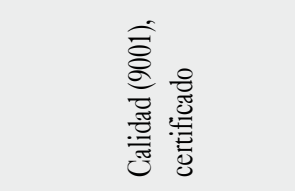 \\
\hline 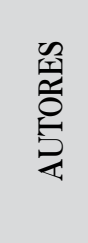 & & \multicolumn{3}{|c|}{ 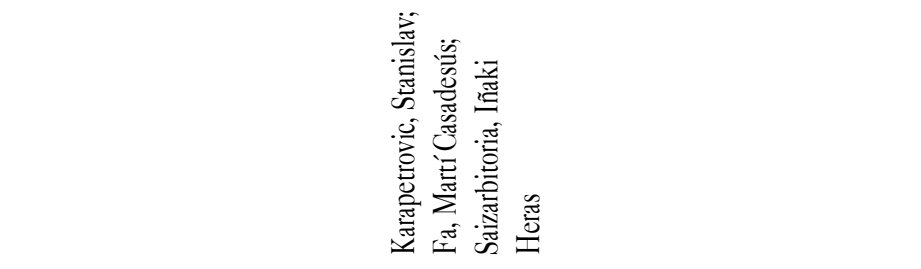 } & 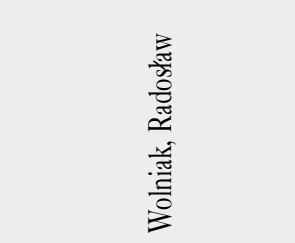 \\
\hline
\end{tabular}




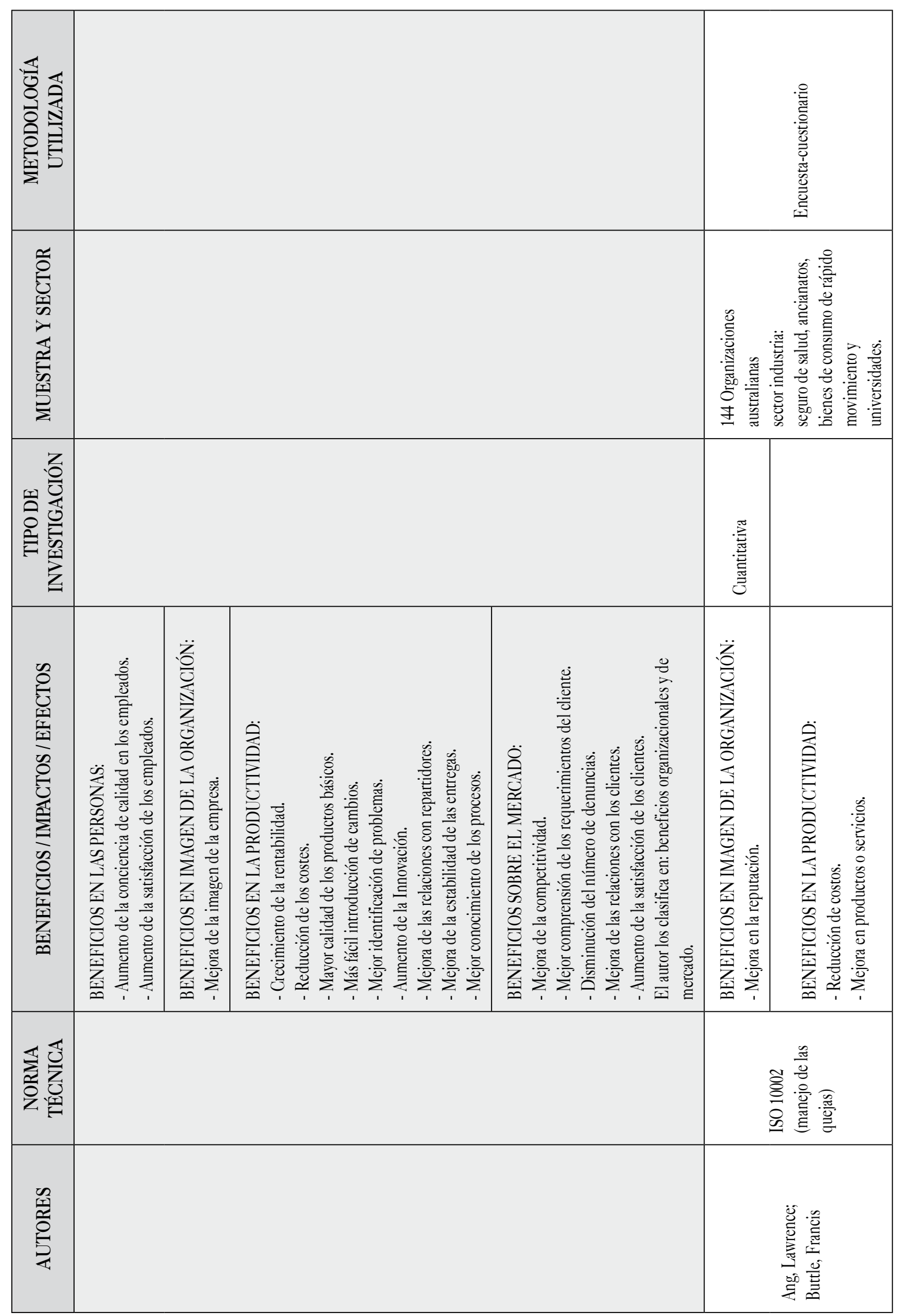




\begin{tabular}{|c|c|c|c|c|c|}
\hline 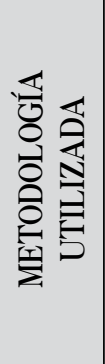 & & 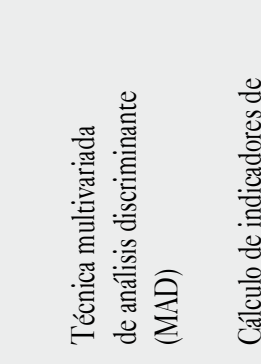 & 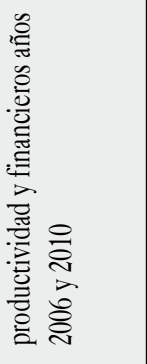 & & 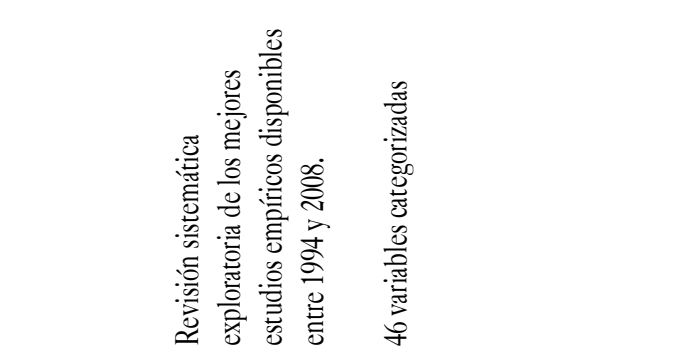 \\
\hline 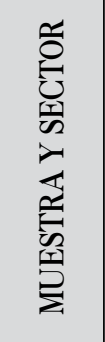 & & \multicolumn{2}{|c|}{ 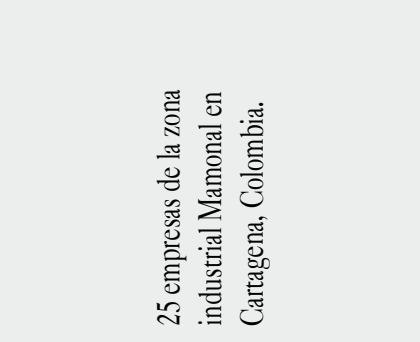 } & \multicolumn{2}{|r|}{ 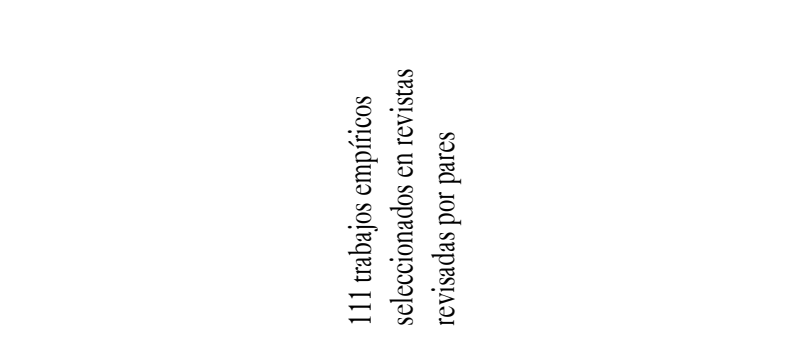 } \\
\hline 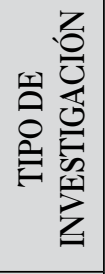 & & \multicolumn{2}{|l|}{ 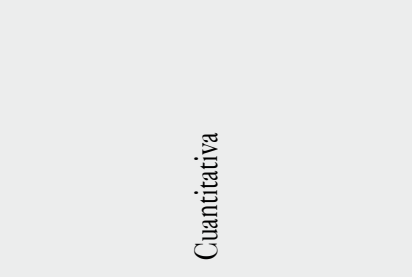 } & \multicolumn{2}{|r|}{ 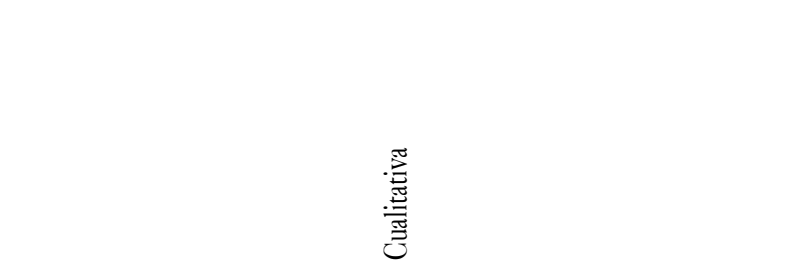 } \\
\hline 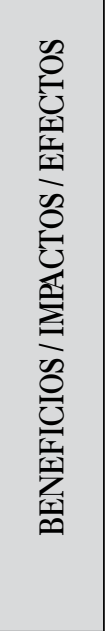 & 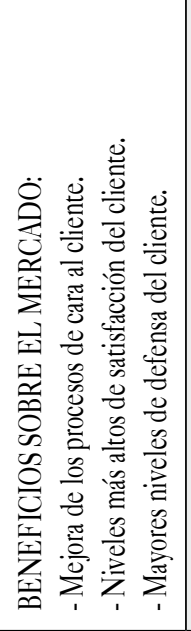 & 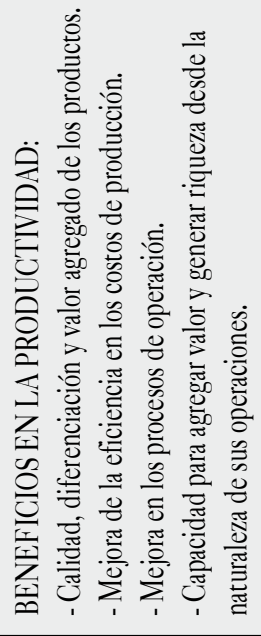 & 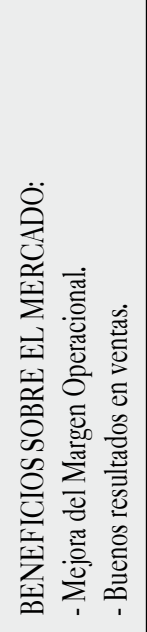 & 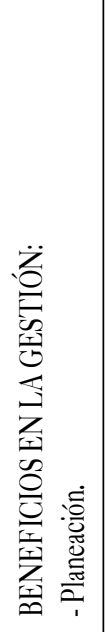 & 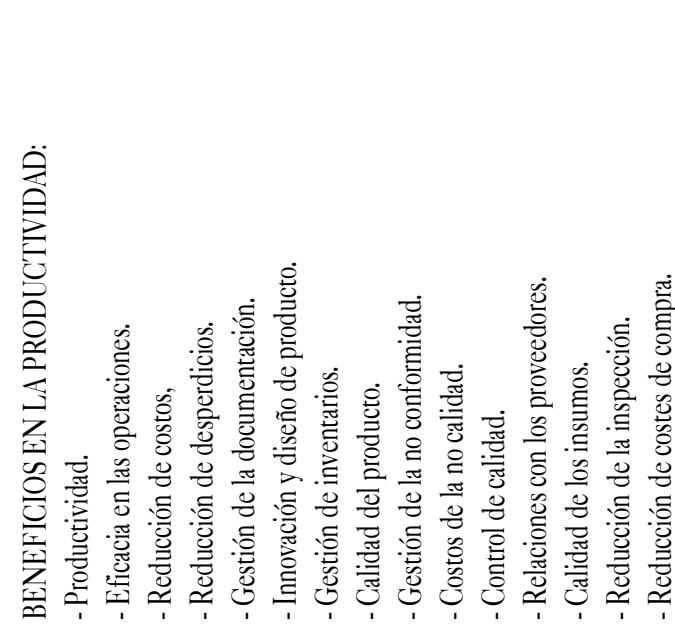 \\
\hline 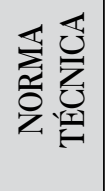 & & \multicolumn{2}{|l|}{ 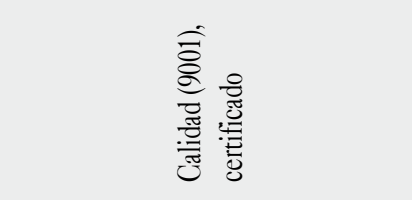 } & \multicolumn{2}{|r|}{ 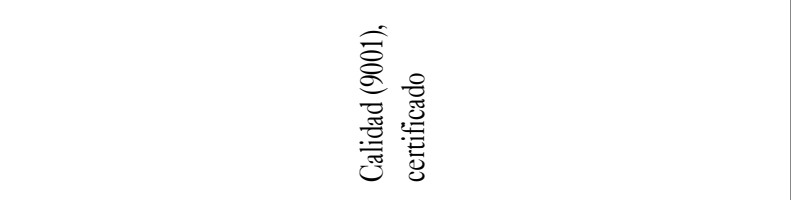 } \\
\hline 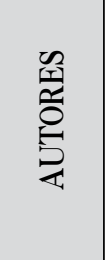 & & \multicolumn{2}{|c|}{ 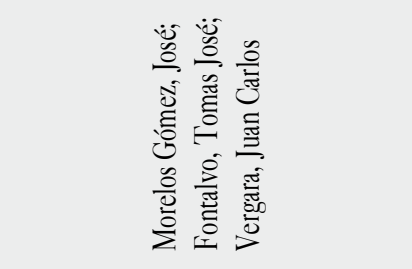 } & \multicolumn{2}{|r|}{ 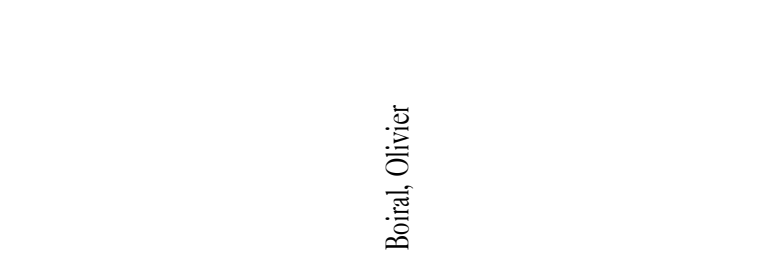 } \\
\hline
\end{tabular}




\begin{tabular}{|c|c|c|c|c|c|c|c|c|}
\hline 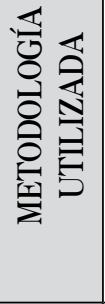 & & & & $\begin{array}{l}\overrightarrow{t_{I}} \\
\end{array}$ & & & & \\
\hline 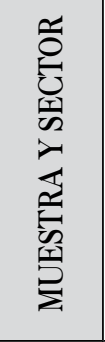 & & \multicolumn{3}{|c|}{ 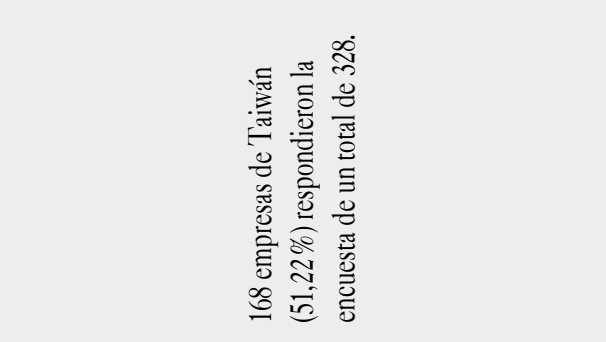 } & \multicolumn{4}{|c|}{ 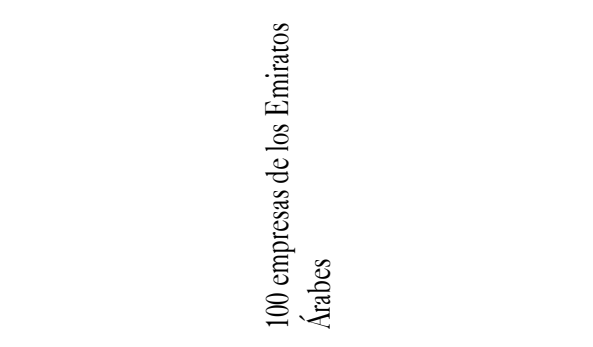 } \\
\hline 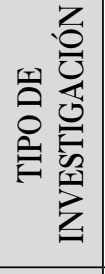 & & \multicolumn{3}{|c|}{ 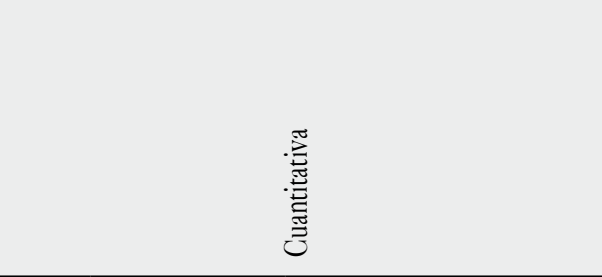 } & \multicolumn{4}{|c|}{ 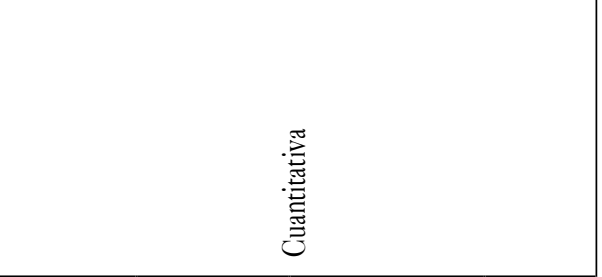 } \\
\hline 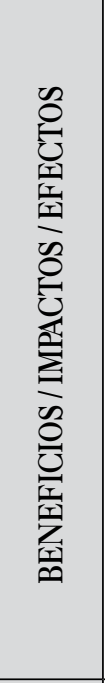 & 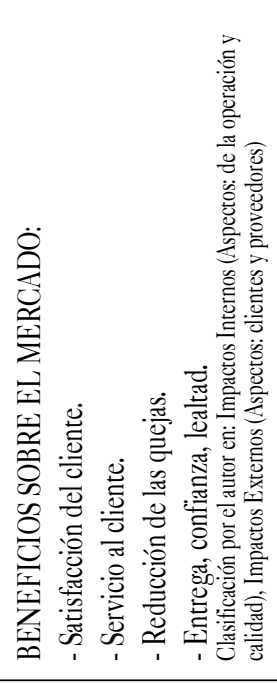 & 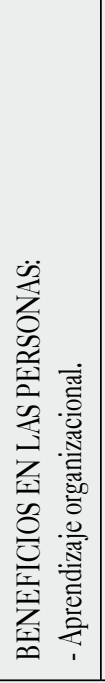 & 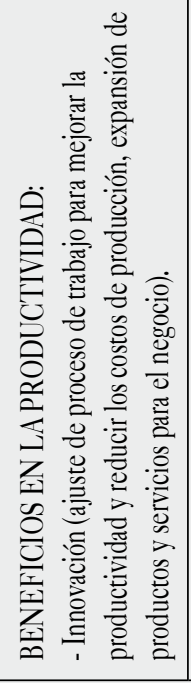 & 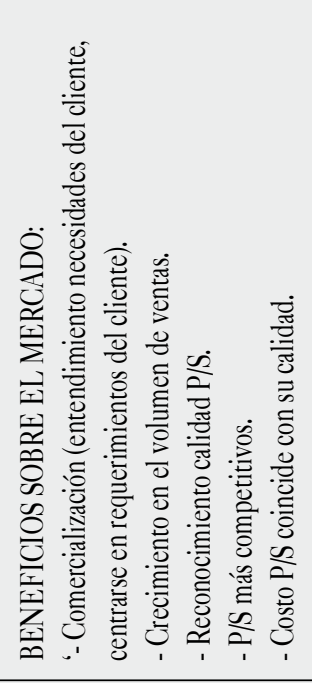 & 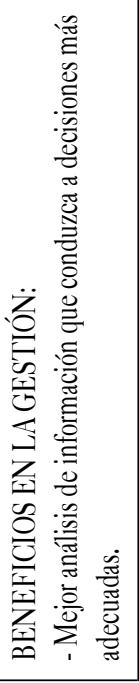 & 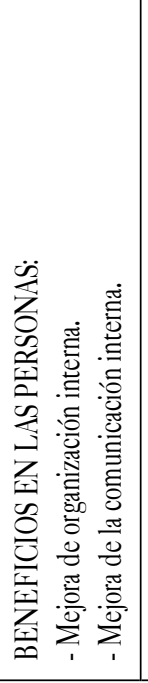 & 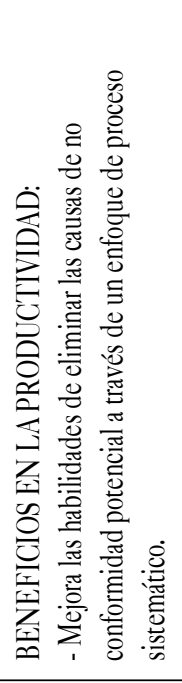 & 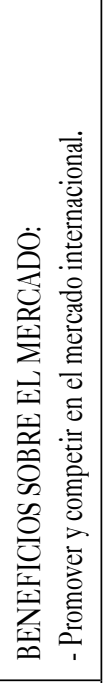 \\
\hline 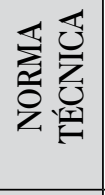 & & \multicolumn{3}{|c|}{ 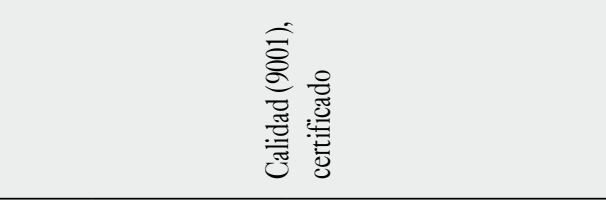 } & \multicolumn{4}{|c|}{ 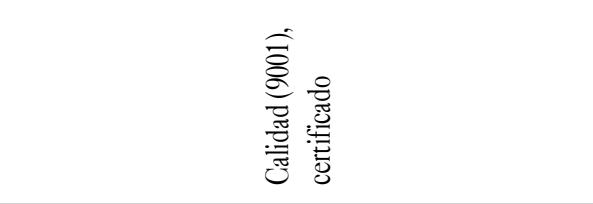 } \\
\hline 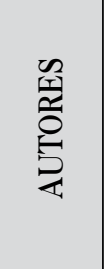 & & \multicolumn{3}{|c|}{ 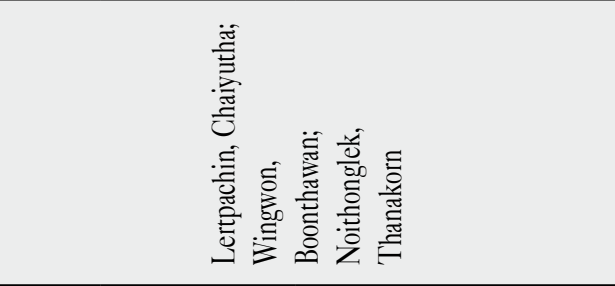 } & \multicolumn{4}{|c|}{ 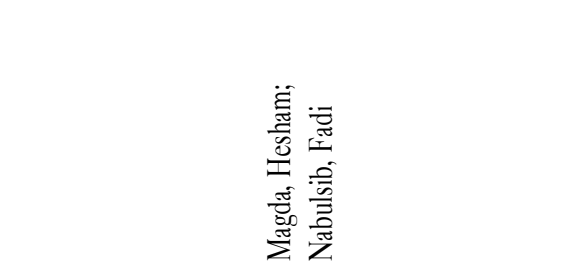 } \\
\hline
\end{tabular}




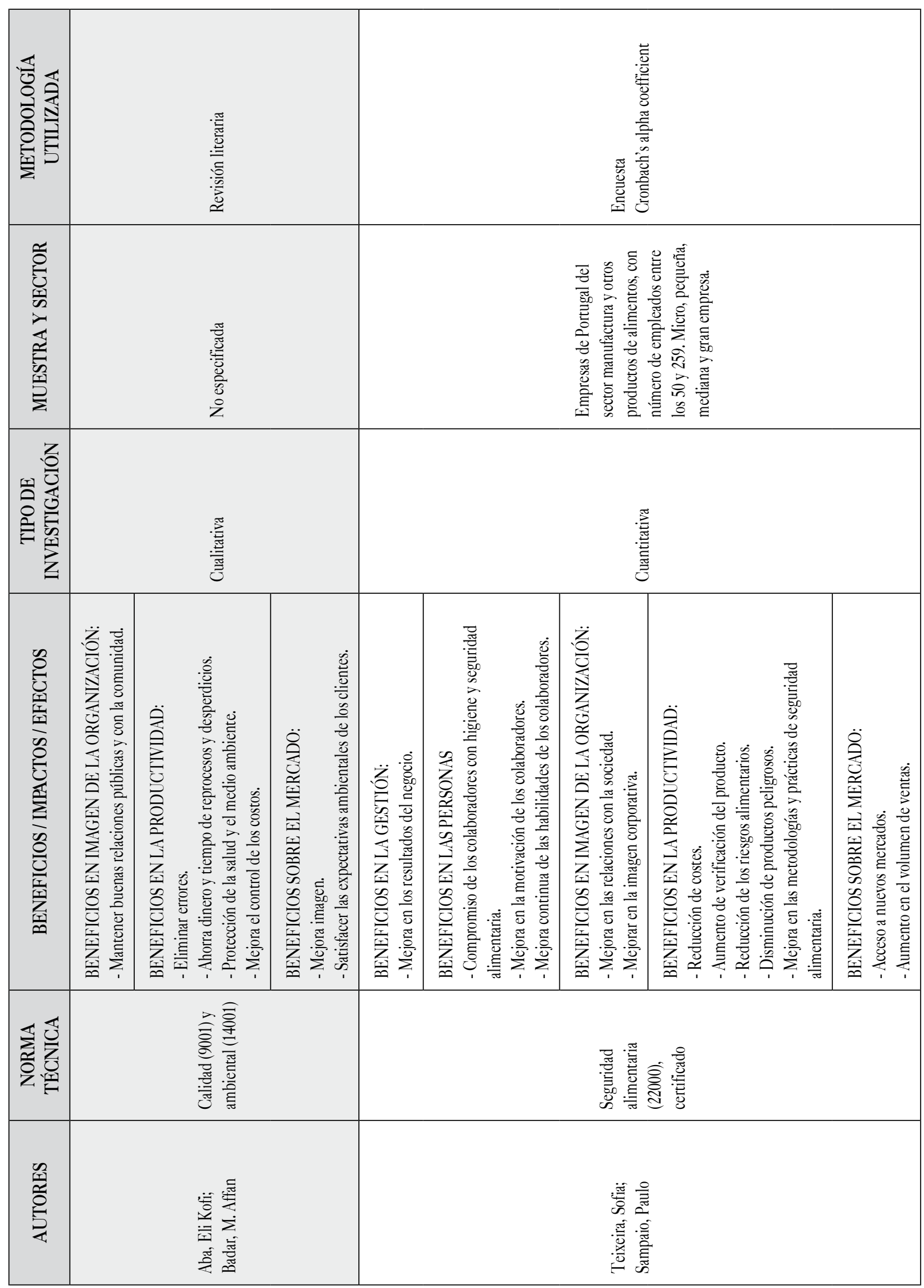


Beneficios e impactos de la implementación de normas técnicas en las organizaciones: una revisión sistemática

\begin{tabular}{|c|c|c|c|c|c|c|c|c|}
\hline 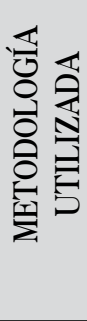 & & \multicolumn{4}{|c|}{ 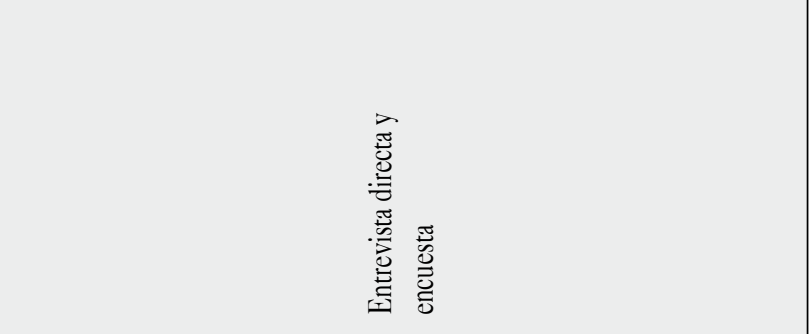 } & \multicolumn{3}{|c|}{ 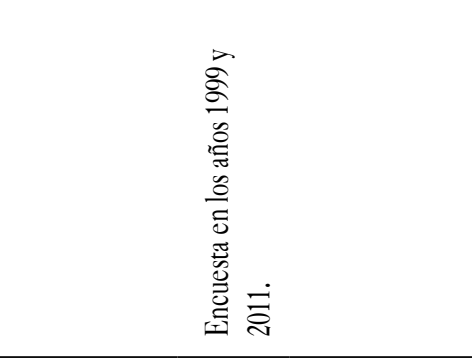 } \\
\hline 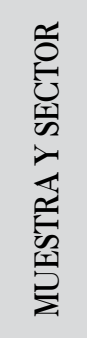 & & & & 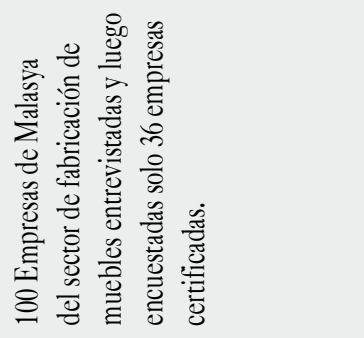 & & \multicolumn{3}{|c|}{ 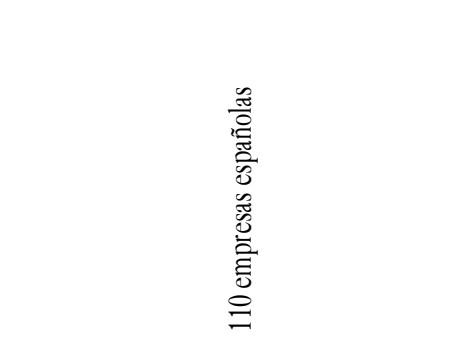 } \\
\hline 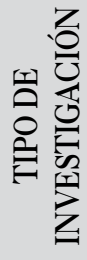 & & \multicolumn{4}{|c|}{$\stackrel{8}{\frac{8}{z}}$} & \multicolumn{3}{|c|}{ 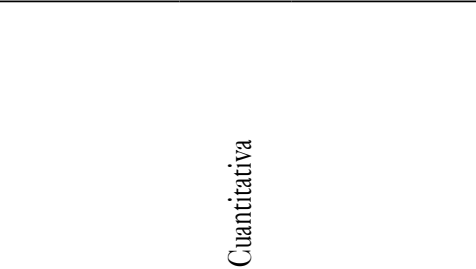 } \\
\hline 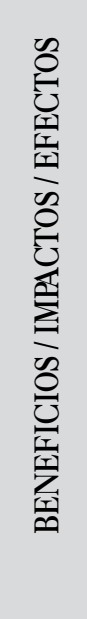 & 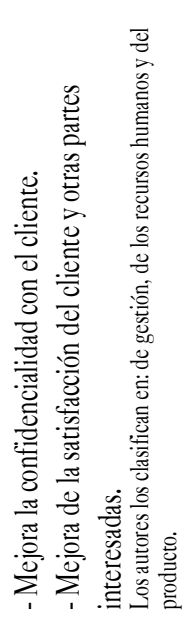 & 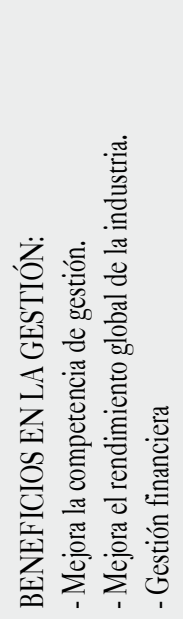 & 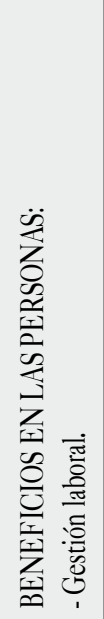 & 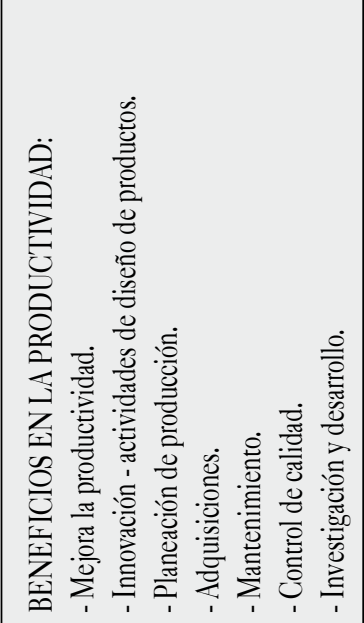 & 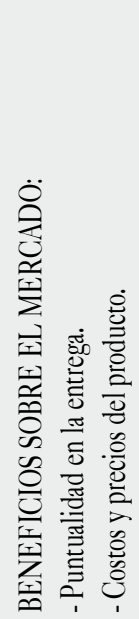 & 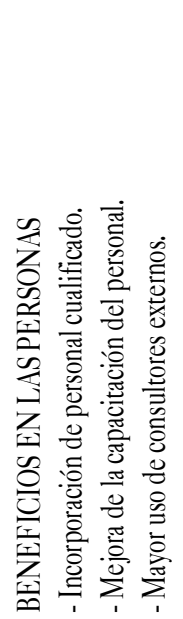 & 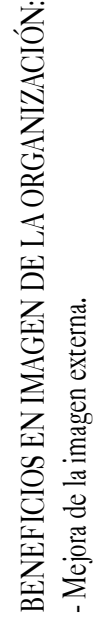 & 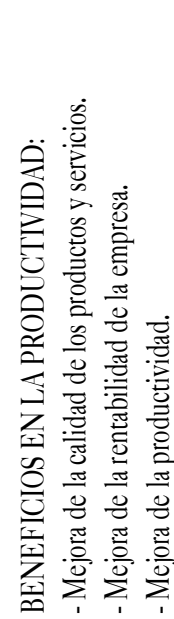 \\
\hline 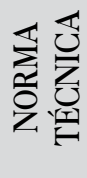 & & \multicolumn{4}{|c|}{ 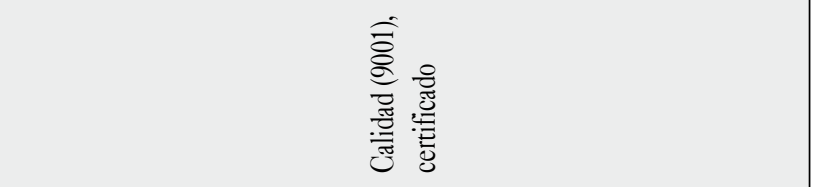 } & \multicolumn{3}{|c|}{ 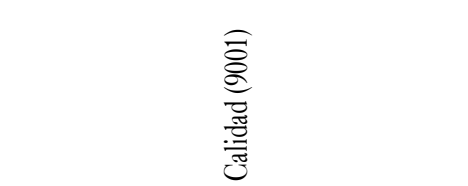 } \\
\hline 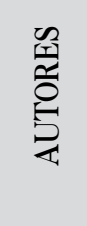 & & \multicolumn{4}{|c|}{ 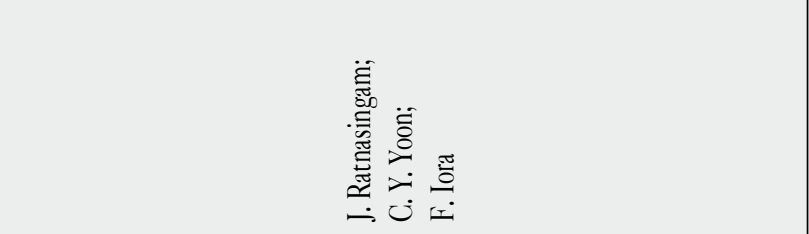 } & \multicolumn{3}{|c|}{ 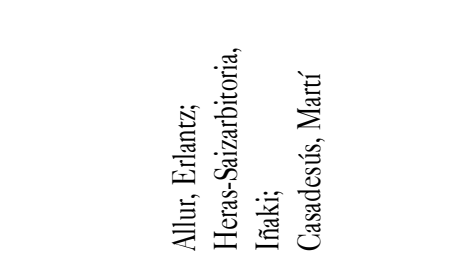 } \\
\hline
\end{tabular}




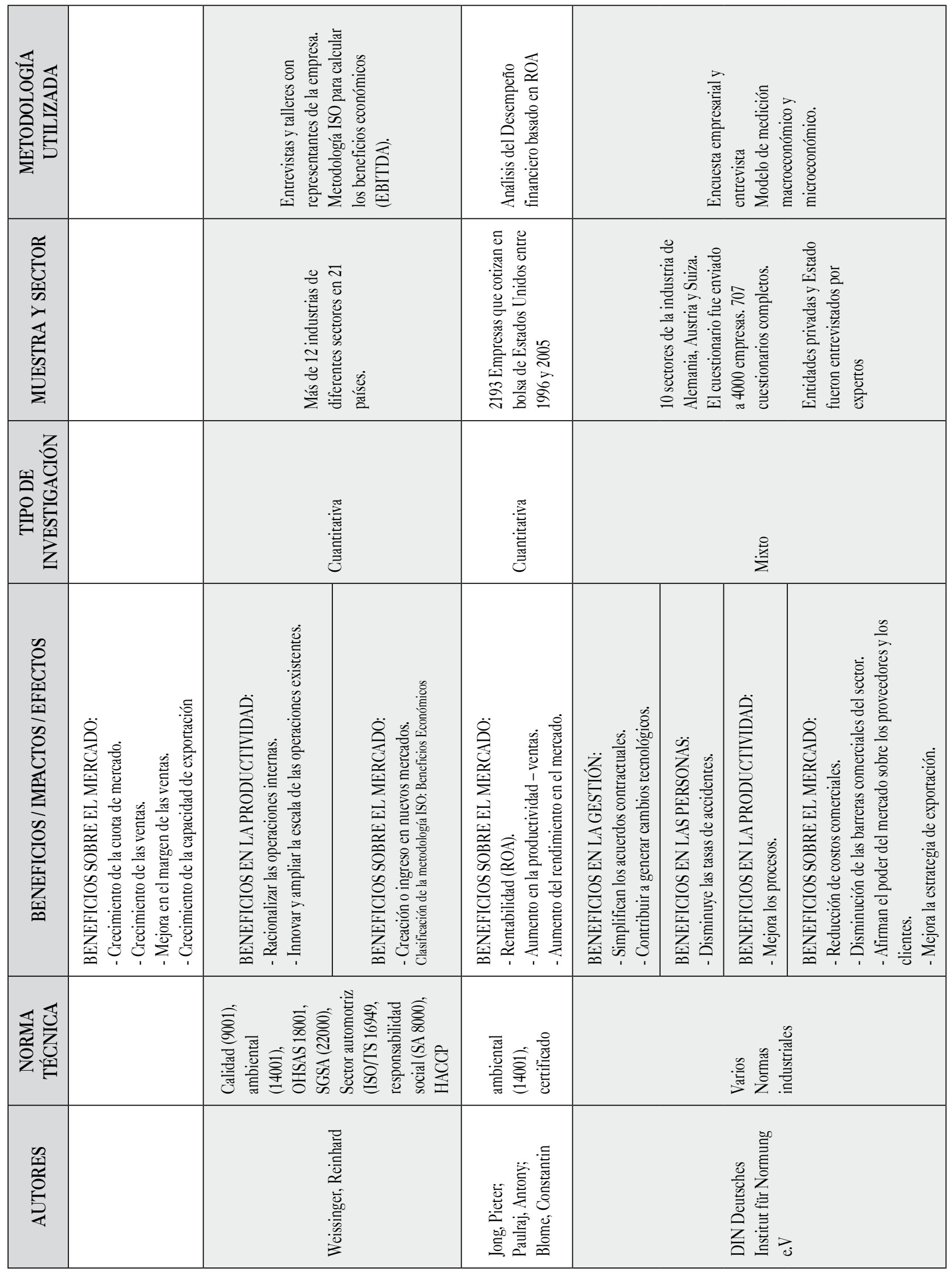




\begin{tabular}{|c|c|c|c|c|c|}
\hline 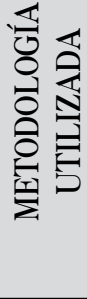 & \multicolumn{5}{|c|}{ 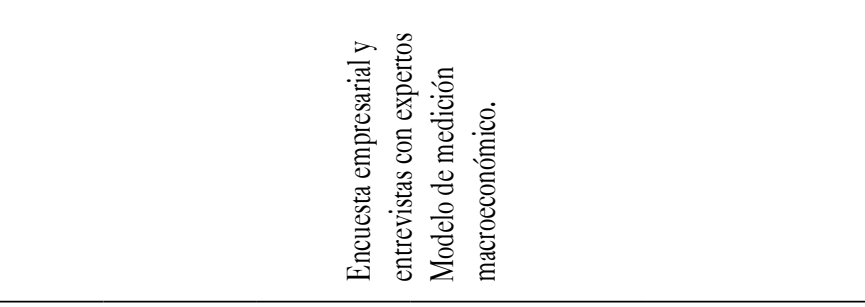 } \\
\hline 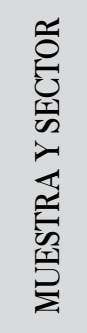 & \multicolumn{5}{|c|}{ 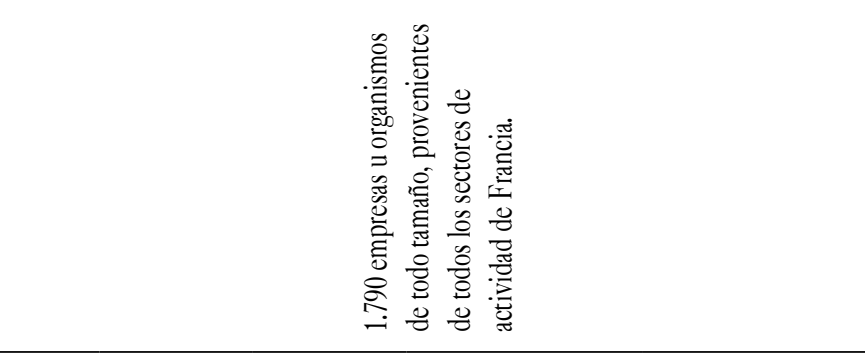 } \\
\hline 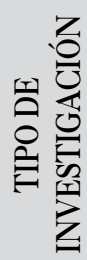 & \multicolumn{5}{|c|}{ 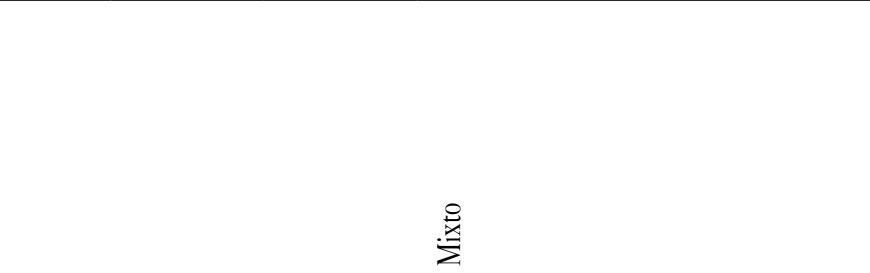 } \\
\hline 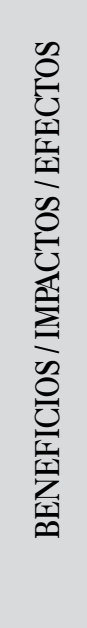 & 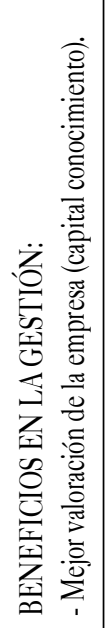 & 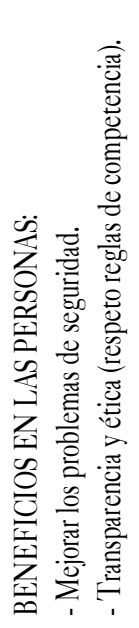 & 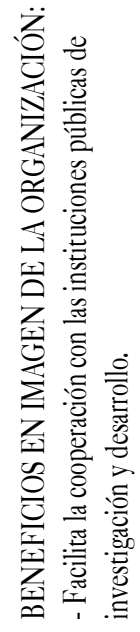 & 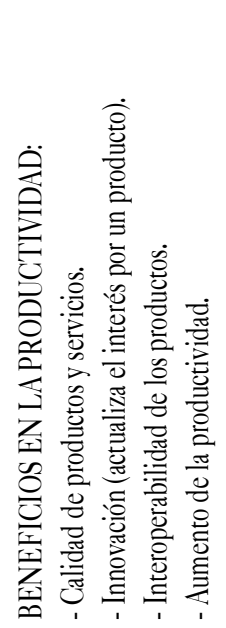 & 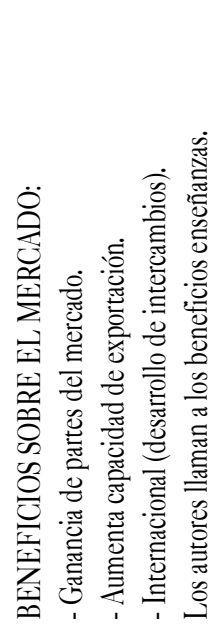 \\
\hline 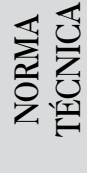 & \multicolumn{5}{|c|}{ 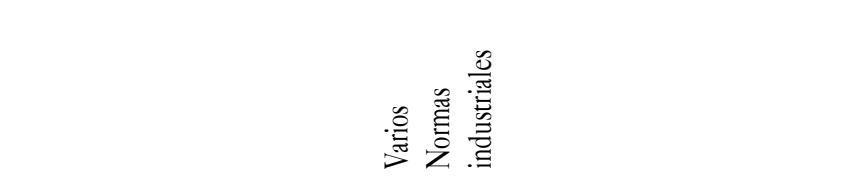 } \\
\hline 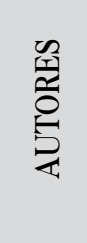 & \multicolumn{5}{|c|}{ 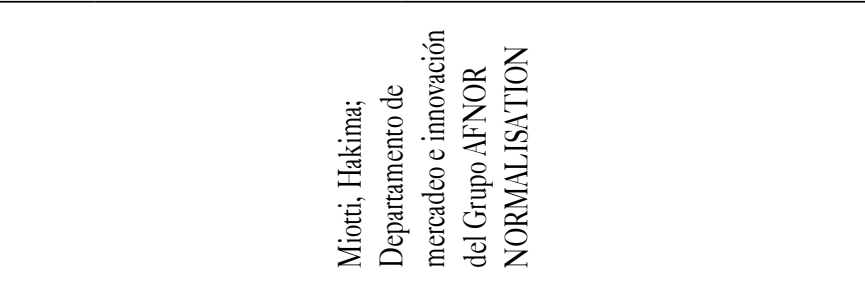 } \\
\hline
\end{tabular}

